\title{
Home Away From Home? Foreign Demand and London House Prices*
}

\author{
Cristian Badarinza and Tarun Ramadorai ${ }^{\dagger}$ \\ This version: November 2016 \\ First draft: November 2013
}

\begin{abstract}
The infrequent nature of crises means that pure time-series methods struggle to distinguish the effects of capital flight on asset prices from a wide range of alternative drivers. We present a new cross-sectional approach, which is motivated by the insight that investors may have different "preferred habitats" within a broad asset class. We apply the method to the question of whether foreign capital is responsible for residential real estate price movements in global cities such as London and New York, especially during crises. Applying our method on large databases of housing transactions over the past two decades, we find that foreign risk strongly affects London house prices. The effects are long-lasting, and are associated with both safe-haven effects and immigration. JEL Codes: C53, D80, E47, F21, G12, G15.
\end{abstract}

\footnotetext{
*The previous version of this paper was circulated under the title "Preferred Habitats and SafeHaven Effects: Evidence from the London Housing Market". We gratefully acknowledge Nationwide Building Society and the Land Registry for providing us with access to the data, and the Alfred P. Sloan Foundation for financial support. We thank Sumit Agarwal, Pol Antras, John Campbell, Alan Crane, Jonathan Cohn, Stijn Claessens, Yongheng Deng, Stefano Giglio, Robin Greenwood, Cam Harvey, Erik Hurst, Ralph Koijen, Tim Landvoigt, Florencio Lopez-de-Silanes, John Muellbauer, Philipp Schnabl, Kevin Sheppard, Andrei Shleifer, Johannes Stroebel and seminar and conference participants at the Saïd Business School, the Oxford-Man Institute of Quantitative Finance, the Oxford Department of Economics, Goethe University, the MIT Sloan Finance Seminar, the Dutch National Bank, the Duisenberg Institute of Finance, Cass Business School, IMF, Imperial College, the University of Texas at Austin, the University of Illinois at Urbana-Champaign, the Darden International Finance Conference, the ABFER Meeting, the NBER Asset Pricing Program Meeting, the Paul Woolley Centre Conference at the LSE, the Federal Reserve Board, Yale University, the National University of Singapore and the 2015 WFA Meetings for useful comments, and Job Boerma and Shuang Zheng for dedicated research assistance.

${ }^{\dagger}$ Badarinza: Department of Real Estate, Institute of Real Estate Studies, 4 Architecture Drive, Singapore 117566, National University of Singapore, and CEPR. Email cristian.badarinza@nus.edu.sg. Ramadorai (corresponding author): Imperial College London, Tanaka Building, South Kensington Campus, London SW7 2AZ, and CEPR. Tel.: +44 20759499 10. Email: t.ramadorai@imperial.ac.uk.
} 


\title{
Home Away From Home? Foreign Demand and London House Prices
}

\begin{abstract}
The infrequent nature of crises means that pure time-series methods struggle to distinguish the effects of capital flight on asset prices from a wide range of alternative drivers. We present a new cross-sectional approach, which is motivated by the insight that investors may have different "preferred habitats" within a broad asset class. We apply the method to the question of whether foreign capital is responsible for residential real estate price movements in global cities such as London and New York, especially during crises. Applying our method on large databases of housing transactions over the past two decades, we find that foreign risk strongly affects London house prices. The effects are long-lasting, and are associated with both safe-haven effects and immigration.
\end{abstract}




\section{Introduction}

There is almost universal acknowledgment that at times of market stress, investors flee towards assets which they perceive as safe. Numerous academics have highlighted that such capital flight can help to explain unusual variation, especially during crises, in the prices of a number of assets, including gold, international real estate, currencies, sovereign debt, and international equities. ${ }^{1}$

Our paper contributes to this important area of research in two specific ways. Our methodological contribution addresses an identification challenge which arises because such demand effects tend to appear during periods of country-specific or global crisis. Historical time-series data is short relative to the frequency of crises, and during such periods of market stress, movements in interest rates and returns, changes in fundamentals or regulation, and the impact of market frictions all tend to move in lockstep. This can severely confound pure time-series identification of asset price movements attributable to capital flight. This identification challenge is compounded by the fact that asset ownership is often opaque and detailed capital flow data can be hard to find.

Our new strategy to identify the effects of demand on asset prices sidesteps these issues. We begin with the insight that investors may be heterogeneous, and have different "preferred habitats" within a broad asset class. ${ }^{2}$ This allows us to develop an empirical methodology which evaluates the asset price elasticity of demand by matching preferred-habitat assets to particular groups of investors, and inspecting the behaviour of prices during periods in which these investors plausibly exhibit demand shocks. This approach provides a significant boost to identification, as it allows us to utilize the power of the cross-section of assets in combination with time-series variation in demand.

Our empirical contribution is to apply this method to a question of public importance. Real estate prices around the world have been particularly volatile over the past few decades, exhibiting dramatic booms and occasional busts. A widely-held view is that foreign capital is at least partly responsible for these gyrations in prices, especially in global cities such as London, New York, and Singapore, which are relatively open to money and immigration from overseas. ${ }^{3}$ However, despite the widespread interest

\footnotetext{
${ }^{1}$ See, for example, Longstaff (2004), Caballero and Krishnamurthy (2009), Beber et al. (2009), Campbell et al. (2010), Baur and McDermott (2010), and Ranaldo and Soderlind (2010).

${ }^{2}$ Preferred habitats have been used extensively to explain the term structure of interest rates (see, for example, Culbertson, 1957, Modigliani and Sutch, 1966, Vayanos and Vila, 2009, and Greenwood and Vayanos, 2010), and individual investor preferences for stocks with similar volatility as their pre-existing holdings (Dorn and Huberman, 2010).

${ }^{3}$ See, for example "Real estate goes global," The New Yorker, 26 May 2014, "Stash pad," New York Magazine, 29 June 2014, "Vancouver's real estate boom: The rising price of heaven," The Globe
} 
in this issue, there is little rigorous empirical evidence that links foreign demand with house prices. This paucity of evidence is at least in part due to the opacity of the ultimate ownership of properties in these cities. To illustrate the scale of this problem, we use a new property-level dataset for London to document that at least $85 \%$ of residential real estate purchases by foreigners in London occurring through a corporation (a preferred vehicle, for tax reasons, over the period) are routed through off-shore special purpose vehicles registered in regions such as the British Islands, Gibraltar, Cyprus, and Panama, meaning that the ultimate source of the capital is essentially untraceable. ${ }^{4}$

Our preferred-habitat identification strategy is motivated by the conjecture that foreign capital directed towards residential real estate will exhibit "home bias abroad," meaning that capital from a source country may be primarily directed towards houses located in areas of the destination city with a high concentration of source-countryorigin residents. We discuss several reasons for the plausibility of this conjecture below. We combine this insight with the observation that foreign demand is generally thought to spike during origin-country crises - for example, London's unusual house price appreciation during the great recession has routinely been explained as the effect of safe-haven demand from foreign buyers. ${ }^{5}$ This means that the usual confounds affecting time-series identification apply here, making our method well-suited to analyzing this problem.

When we employ our method on large databases of historical housing transactions in London, we find evidence that foreign demand is indeed an important part of the explanation for house price movements in London, and that this has been the case not only during the most recent crisis period, but consistently throughout the past few decades. As we describe in the paper, we go on to derive additional insights about this phenomenon which enrich the current public debate. We also note here that our identification approach seems particularly well-suited for this context, since it does not depend on the use of detailed ownership data, estimating the effects in the destination

and Mail, 10 October 2014, and "Immigration is driving up home prices," Daily Mail, 26 October 2014.

${ }^{4}$ This issue has been explictly connected in the press to motives for wealthy individuals to keep such details private. See, for example "Towers of Secrecy: Stream of Foreign Wealth Flows to Elite Real Estate," The New York Times, 7 February 2015, and "A Long Days' Journey Into Knightsbridge", The Financial Times, 10 November, 2015. In a more recent examination of the question of foreign investors' effects on the London housing market, Sa (2016) also studies the new property-level dataset in detail.

${ }^{5}$ See, for example "Rule of law is central to London's safe haven status," The Financial Times, 11 March 2013, "London remains top safe haven for property investors", The Telegraph, 13 March 2013, "Live and let buy: Why an influx of foreign money is good for London's property market," The Economist, 9 November 2013. 
market directly under our identification assumptions. ${ }^{6}$

To illustrate our identification strategy, consider that in late 2009 and early 2010, there were large shocks to economic and political risk in Greece. To detect whether this generates Greek demand for properties in London, we conjecture that areas of London with relatively high pre-existing shares of Greek-born residents are preferred locations for Greek property purchases. If this conjecture is correct, following heightened risk in Greece, we would expect to see relatively higher prices in these specific areas of London, over and above the general level of London house prices. We note that concerns of reverse causality or simultaneity (where London sub-area price increases drive Greek aggregate risk, or where Greek aggregate risk shocks are driven by the same factors which later drive property prices in sub-areas of London), appear less plausible in this setup. ${ }^{7}$

We generalize this insight, sub-dividing London into smaller geographical units, and enumerating the strength of the links of each London sub-area with specific foreign countries. When risk in a foreign country rises, our specifications forecast intraLondon rates of price appreciation in proportion to the strength of the links between London areas and the foreign country. We measure these links using the share of the population of each London sub-area (624 electoral wards in our empirical application) which originates from different countries, but this can easily be generalized to other preferred-habitat indicators of the attractiveness of particular areas of London to specific countries.

Why is it sensible to link particular foreign countries to areas of London in this way? First, at least some portion of housing demand is likely to be driven by calculations of subsequent physical movements, i.e., the potential for subsequent immigration to London. If so, the cultural affinity of prospective immigrants for their future neighborhoods in London is very likely to affect their real estate demand. This line of reasoning does not require the immigration to materialize, only that it is a factor influencing property selection. That said, we find evidence that patterns of growth in ward-level immigration shares in our data are consistent with this line of reasoning. ${ }^{8}$

\footnotetext{
${ }^{6}$ All of our specifications control for the influence of a large set of hedonic property characteristics that are likely to influence London house prices, using the now standard approach of Rosen (1974). A recent example of the use of hedonic regressions to explain house prices is Campbell et al. (2011). Meese and Wallace (1997) discuss the benefits of the hedonic pricing method, relative to one based on repeat sales (for examples of the latter, see Case and Shiller (1987), and Bollerslev et al. (2013)).

${ }^{7}$ It is of course possible (but we believe unlikely) that the effects of an omitted factor are perfectly aligned with the residual distribution of house price changes across wards within each borough and simultaneously - across the entire set of countries of origin.

${ }^{8}$ Interestingly, Saiz and Wachter (2011) find evidence from the US that growing immigration density leads to native flight and slower rates of house price appreciation, and Sa (2015) finds that immigration is associated with declines in house prices in local authorities in the UK between 2003
} 
Second, even if an implicit or explicit future immigration motive is not a factor affecting purchasing decisions, there may be social network effects associated with foreign-origin settlement in particular London areas. These may help to lower informational asymmetries in property purchases, through direct communication between foreign-origin local London residents and overseas buyers, or because of specialty realtors, local legal firms, and other soft infrastructure set up to match overseas purchasers of specific nationalities with property investment opportunities in specific London areas. ${ }^{9}$ Third, connection between foreign purchasers and country-of-origin London residents may facilitate monitoring of the physical investment, that is, property maintenance or managing rental tenants. This is an especially useful service when purchasers are located in a different country.

The foreign demand effects that we uncover are precisely estimated, but likely to be an underestimate of the true effect size, as we eliminate effects with homogenous impacts across London in an effort to achieve sharp causal identification. We find that in London areas with high (top quintile) shares of people originating from a particular country, house prices rise by an average of 1.41 percentage points and housing transaction volumes by 1.84 percentage points two years after an episode of elevated risk in that country. In terms of overall magnitudes, we estimate that foreign demand accounts for at least $7.9 \%$ of the total variation of London house prices over the sample period. As we describe more fully in the paper, we conduct a battery of placebo tests and simulations to verify that these estimated effects are robust.

Having estimated these effects, we evaluate their economic underpinnings. We do so by relating the estimated price effects to patterns of capital flows and immigration into the UK, and find evidence that both "safe-haven" motivations for capital preservation as well as patterns of cross-border migration are at play.

Our work is related to a number of different literatures. As mentioned earlier, our approach connects our work to the literature on estimating safe-haven effects in a variety of assets, which has tended to use time-series rather than cross-sectional approaches to this problem. Our findings confirm that risk in a number of countries predicts house prices in London over and above hedonic characteristics, suggesting that

and 2010. Ottaviano and Perri (2006) show that such effects are compensated in the long run by the positive contribution of cultural diversity to economic growth. This evidence makes it more likely that the "safe-haven for capital" channel is the principal source of the effects that we detect, rather than the direct immigration channel, though we find evidence that both are prevalent.

${ }^{9}$ See, for example, London-Tokyo property services (http://www.londontokyo.co.uk/en/aboutus.php), and Celestial Globe (http://www.celestialglobe.co.uk/en/) which have been established to help prospective Japanese and Chinese buyers, respectively, in the London property market. The branch locations and property listings of each of these organizations appear concentrated in particular London areas. 
the resultant cross-border investments generate price pressure in destination country assets. In this sense, our paper confirms the view that cross-border capital flows can act as a channel for the international transmission of risk, joining a growing list of papers including Kaminsky et al. (2004), Broner et al. (2006), and Jotikasthira et al. (2012). ${ }^{10}$ Our use of "home bias abroad" for identification connects our study to work on home-bias and portfolio choice (see, for example Coval and Moskowitz, 2001), as well as to work on the effect of "preferred habitats" on portfolio choice referenced earlier.

Finally, our work contributes to the burgeoning literature on the determinants of real estate prices. ${ }^{11},{ }^{12}$ Our use of the foreign-origin share links our paper with the work of Card and DiNardo (2000), Card (2001), and Saiz and Wachter (2011). Aizenman and Jinjarak (2009), Jinjarak and Sheffrin (2011), and Favilukis et al. (2013) analyze how foreign capital flows affect house prices - our work is distinguished from these papers by our novel cross-sectional approach, and our implementation using transaction data. We also note that our method can be adapted easily to any context in which legal barriers prevent the exact assignment of capital flows to their ultimate source, which makes it a promising strategy for similar identification in other opaque or unregulated markets.

The remainder of the paper is organized as follows. Section II describes our approach, beginning with a simple illustration of the method. Section III describes the data that we employ. Section IV presents the results from our baseline empirical estimation. Section V considers a number of robustness checks and placebo tests and simulations. Section VI explores how these safe-haven effects in the residential real estate market relate to patterns of capital flows and immigration, and Section VII concludes. An online appendix contains supplementary results and robustness checks, and is available at the URL specified in the references section.

\footnotetext{
${ }^{10}$ See Claessens and Forbes (2001) and Karolyi (2003) for surveys of the literature on international financial contagion.

${ }^{11}$ See, for example, Brunnermeier and Julliard (2008), Mian and Sufi (2009), Goetzmann et al. (2012), Gyourko, Mayer, and Sinai (2013), Ngai and Tenreyro (2014), Choi, Hong, Kubik, and Thompson (2015), and Stroebel and Vavra (2015).

${ }^{12}$ Our notion of a spatial equilibrium in which the preferred assignment in the real estate market between buyers and property types leads to price appreciation in the short-run and cross-regional convergence in the long run is in the tradition of Braid (1981), Guerrieri et al. (2013), and Landvoigt et al. (2015).
} 


\section{Methodology}

This section describes the method that we employ to identify foreign demand effects on London house prices. To motivate our analysis, we first describe the time-series evolution of house prices in London relative to the remainder of the UK, and explore how this pattern relates to time-series variation in foreign risk. To aid the development of insight about our new approach, we then illustrate it very simply using a series of maps of London. The final part of this section describes our approach more rigorously.

\section{A. Time-Series Patterns}

The top panel of Figure 1 shows the widely documented emergence of a house price gap between London and the rest of the UK. The figure uses indexes reported by Nationwide, Halifax (now owned by Lloyds), the Land Registry, and the UK Office of National Statistics, and plots the hedonic-adjusted percentage spread between the price of the average house in London relative to a population in 2001- weighted average house price in the remainder of the UK.

All four series clearly show that the spread between London house prices and those in the remainder of the UK is very large on average. Moreover, this spread fluctuates substantially over time. There is a pronounced increase in this spread beginning in 1998, a period of heightened international political and economic uncertainty owing to the Asian and Russian financial crises. Following this period, London prices appear to grow at roughly the same rate (or a slightly lower rate) as those in the remainder of the UK during the early part of the decade beginning in 2000. Finally, there is strong growth in the spread following the onset of the financial crisis beginning in 2008.

The bottom panel of Figure 1 shows the relationship between the London house price spread and a 1-year trailing moving average of the ICRG political risk index, weighted by the extent to which people born in each foreign country are represented in London's population, across all of the non-UK countries in our sample available in each time period. The plot clearly shows that in time-series, these indicators of foreign risk appear closely related with the spread between London house prices and those in the remainder of the UK.

These patterns are visually striking. However, as mentioned earlier, time-series analysis does not allow us to derive precise inferences, or to attribute causality, because of the possibility of common shocks affecting aggregate house price variation and measures of risk. 
Figure 1

Evolution of the London housing market

Panel A shows the evolution of London house prices relative to the UK. We collect the alternative series reported by four different UK institutions and aggregate the regional indexes by using 2001 census population weights. The indexes produced by Nationwide, the Lloyds Group and the ONS are based on data on mortgage loans. The one from the Land Registry is based on repeat sales. Panel B shows lagged monthly 1-year moving averages of the ICRG measure of political risk. We generate aggregate values by weighting the observations according to the respective population shares in London. The ICRG indicators are normalized by subtracting the in-sample mean and dividing by the standard deviation.

Panel A

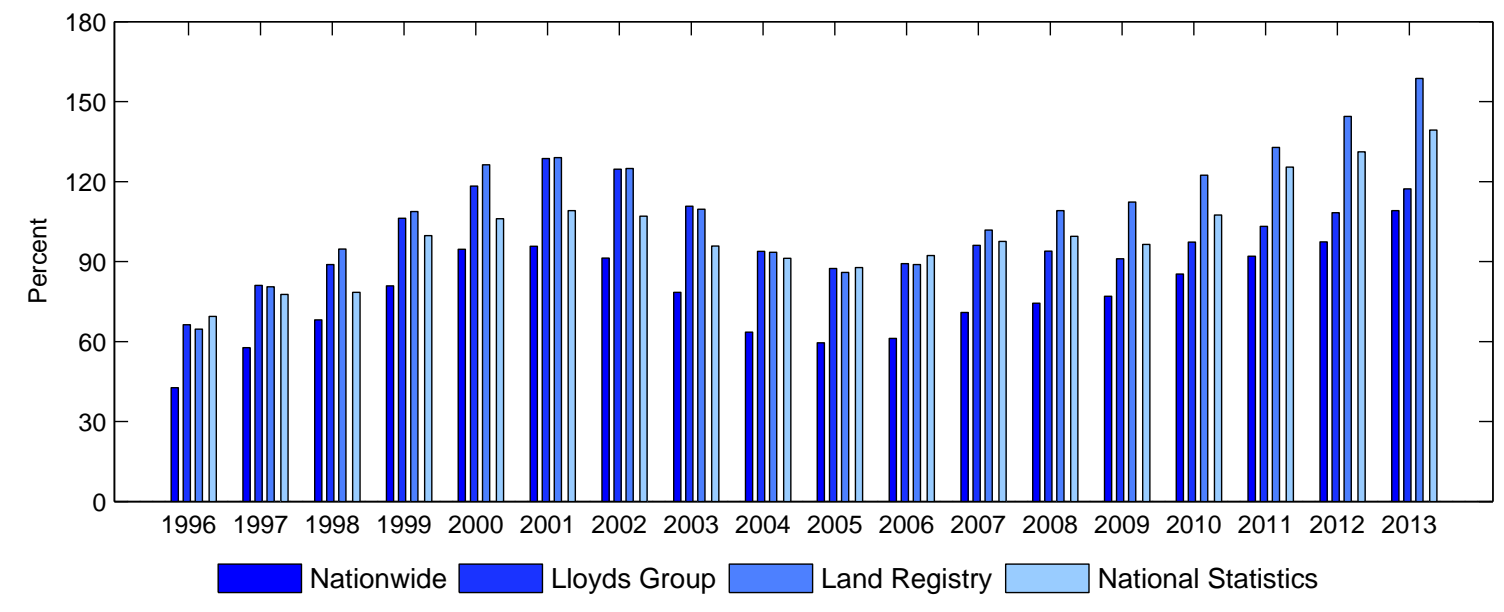

Panel B

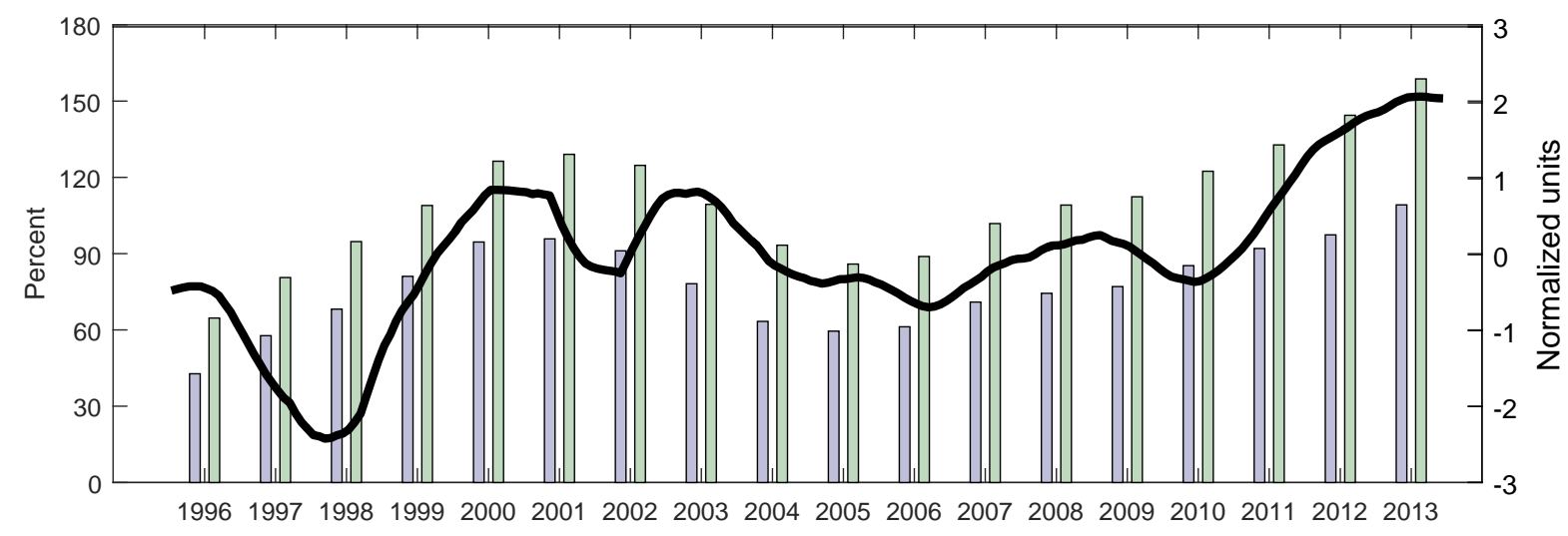

London HPI spread (Nationwide)

London HPI spread (Land Registry)

ICRG indicator of political risk (normalized; lagged 12-months MA; right axis) 


\section{B. Cross-border Ownership of Residential Real Estate}

If precise ownership information of London properties were available, it would aid in identification of safe-haven effects, to the extent that we could estimate the correlation between foreign purchases of London real estate and risk shocks in the country of origin.

We therefore acquire publicly available data on the complete set of residential properties in London owned by foreign-owned corporate entities (we note that purchasing through a corporate entity was a popular tax avoidance device over the period for foreign residential purchases). The dataset details the location of the property, the time of purchase, and the country of residence for the primary owner. However, as we report in Table 1, most purchases by foreign-owned entities are directed through off-shore vehicles, which mask the ultimate source country of the capital. For more than $85 \%$ of the properties in the data, the foreign corporate owner is registered as located in areas such as the British Islands, Panama, Cyprus, and the Seychelles. ${ }^{13}$ To make progress, therefore, we need to develop a method to permit identification of foreign demand effects on London house prices which does not rely on these ownership data, but which does permit a deeper characterization of the underlying economic motivations for this demand. The next subsection provides a simple illustration of our proposed method.

\section{Illustrating the Method Using the Total Foreign-Origin Share}

Figure 2 provides a preliminary illustration of our method and main results. The panels in the figure show maps of London, with its 624 electoral wards (our unit of London sub-location) color-coded in a "heatmap," where red (blue) shades indicate greater (lower) levels of particular variables. Panel A of the figure shows the average house price appreciation in London electoral wards between 2001 and 2006, a period of relatively low global uncertainty. Panel B of the figure shows the average house price appreciation in London electoral wards between 2007 and 2012, a period of elevated global risk.

When juxtaposed, the figures show that the centre and northwest of London experienced significant house price appreciation during the period of elevated risk. Panel C of the figure shows that properties located in the areas of appreciation in Panel B are relatively more likely to be owned by foreign entities. Ideally, we would exploit this cross-sectional pattern for the identification of safe-haven effects.

\footnotetext{
${ }^{13}$ Importantly the data also show that the question of foreign ownership is not restricted to purchases in the Prime Central London area, but is widely spread across the city (see Panel C in Figure $2)$.
} 


\section{Table 1}

\section{Cross-border ownership of residential properties in London}

This table reports the number of properties owned by corporate entities registered in different countries, relative to the total foreign-owned residential housing stock in London. The source of the data is the October 2015 release of the Land Registry's Overseas Companies dataset.

\begin{tabular}{|c|c|c|c|c|c|}
\hline Country of origin & Share & $\begin{array}{l}\text { Cum. } \\
\text { share }\end{array}$ & $\begin{array}{l}\text { Country of origin } \\
\text { (continued) }\end{array}$ & Share & $\begin{array}{l}\text { Cum. } \\
\text { share }\end{array}$ \\
\hline Jersey & $26.6 \%$ & $26.6 \%$ & Liechtenstein & $0.9 \%$ & $88.0 \%$ \\
\hline Isle of Man & $14.5 \%$ & $41.1 \%$ & Marshall Islands & $0.9 \%$ & $88.8 \%$ \\
\hline Guernsey & $13.4 \%$ & $54.5 \%$ & Italy & $0.7 \%$ & $89.6 \%$ \\
\hline Panama & $5.7 \%$ & $60.2 \%$ & Delaware & $0.7 \%$ & $90.3 \%$ \\
\hline Singapore & $3.5 \%$ & $63.7 \%$ & Japan & $0.6 \%$ & $91.6 \%$ \\
\hline Cyprus & $3.3 \%$ & $67.0 \%$ & St Kitts and Nevis & $0.6 \%$ & $92.2 \%$ \\
\hline Gibraltar & $3.2 \%$ & $70.2 \%$ & Switzerland & $0.6 \%$ & $92.8 \%$ \\
\hline Netherlands & $3.1 \%$ & $73.3 \%$ & Turks Islands & $0.5 \%$ & $93.3 \%$ \\
\hline Seychelles & $2.8 \%$ & $76.1 \%$ & Nigeria & $0.4 \%$ & $93.7 \%$ \\
\hline Ireland & $2.5 \%$ & $78.5 \%$ & France & $0.4 \%$ & $94.1 \%$ \\
\hline Luxembourg & $2.3 \%$ & $80.8 \%$ & Malaysia & $0.4 \%$ & $94.5 \%$ \\
\hline Hong Kong & $2.1 \%$ & $82.9 \%$ & Sweden & $0.4 \%$ & $94.8 \%$ \\
\hline Liberia & $1.8 \%$ & $84.7 \%$ & Spain & $0.3 \%$ & $95.5 \%$ \\
\hline USA & $1.7 \%$ & $91.0 \%$ & New Zealand & $0.3 \%$ & $95.7 \%$ \\
\hline Mauritius & $1.3 \%$ & $86.0 \%$ & UAE & $0.2 \%$ & $96.0 \%$ \\
\hline Germany & $1.1 \%$ & $87.0 \%$ & Others & $4.0 \%$ & $100.0 \%$ \\
\hline
\end{tabular}


Figure 2

House prices, ownership patterns and demographic structure at ward level

The figure reports the cross-sectional distribution of house prices and characteristics, across the 624 London electoral wards. In Panels A and B, we plot the increase in average ward-level prices for two different sub-periods, calculated in the Land Registry sample of housing transactions. Panel C illustrates the number of residential properties in each ward that are owned by a foreign corporate entity, as reported by the Office for National Statistics. Panel D shows the ward-level fraction of people born outside the UK, as indicated in the 2001 census.

A: House price appreciation between 2001 and 2006

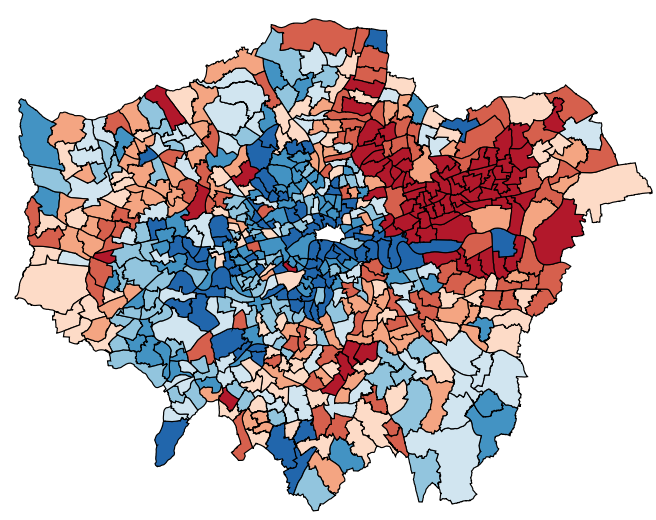

C: Cross-border ownership (Oversears Companies Database)
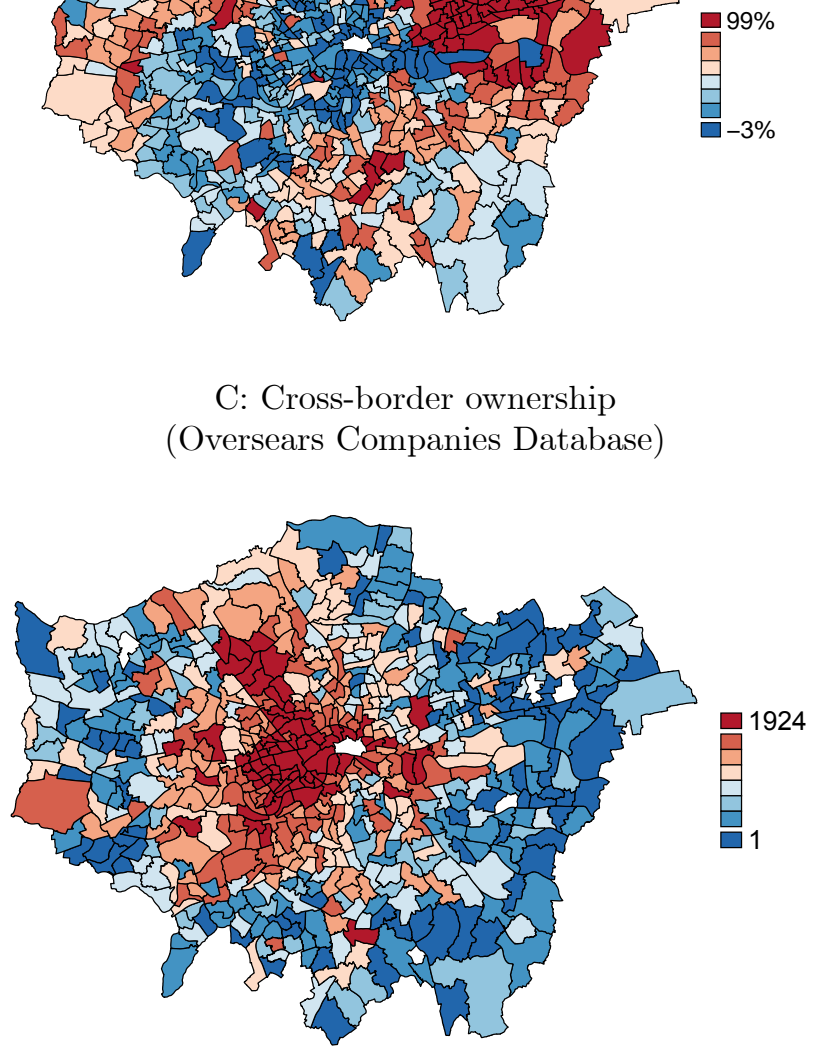

B: House price appreciation between 2007 and 2012

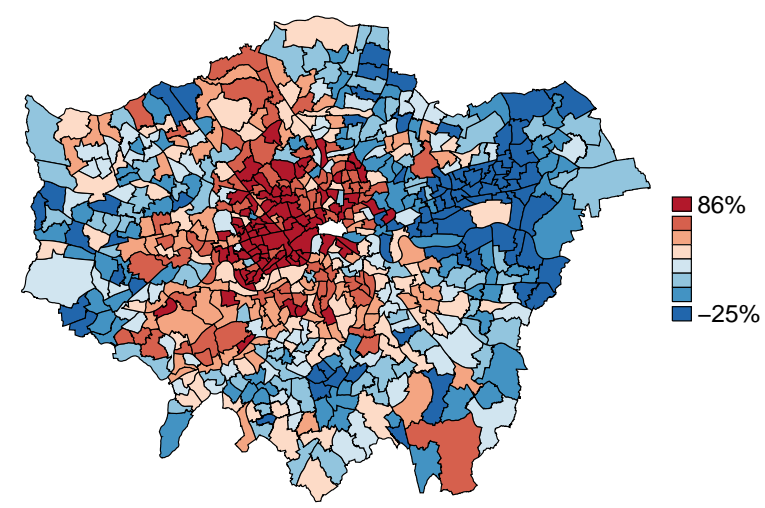

D: Foreign-born people share (UK Census)

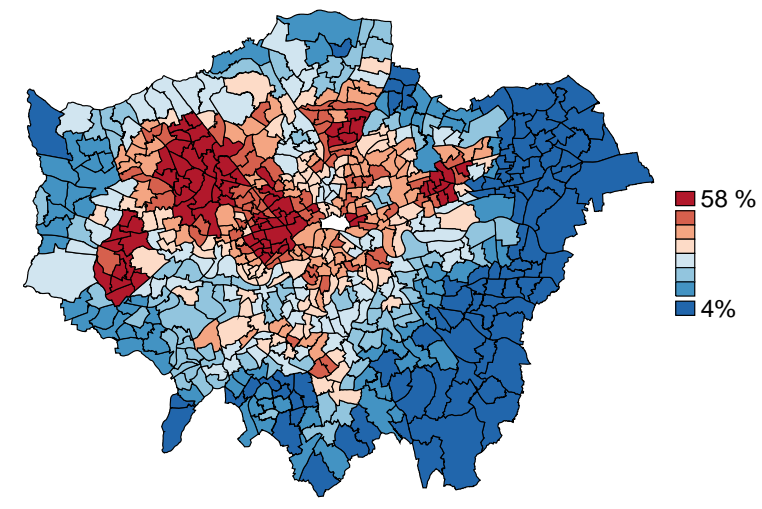


However, as described above, the ultimate ownership information is rendered inaccurate by the use of off-shore vehicles. This poses a measurement challenge which we address under our assumption of "home bias abroad," using the geographic distribution of the countries of origin of the pre-existing resident population.

This country of origin information is well measured in official census data, and Panel D of the figure shows the total share of foreign-origin people in London wards from the 2001 census.

The relationship between Panel B and Panel D is clearly evident from the plot, lending credence to our identification assumption. House price appreciation between 2007 and 2012 in Panel B shifts away from the locations in Panel A, and lines up well with the share of foreign-origin people in London wards in Panel D. Indeed, the simple cross-ward correlation between 2001-2006 price appreciation and 2001 foreign-origin shares is $-12 \%$, while the cross-ward correlation between 2007-2012 price appreciation and 2001 foreign-origin shares increases to $+38 \%$.

We now turn to describing our method more rigorously.

\section{Estimating Foreign Demand Effects}

Consider the following hedonic pricing model for residential properties in London:

$$
\ln P_{i, t}=\alpha+\phi_{w}+\Pi_{w, t}+\boldsymbol{\beta} \boldsymbol{X}_{i, t}+u_{i, t}
$$

Here, $P_{i, t}$ is the price of property $i$ (which is physically located in location $w$ within London), measured in quarter $t . \boldsymbol{X}_{i, t}$ is a vector of hedonic characteristics for property $i$. Our identification strategy is to study the variation in the location $(w)$ cross time $(t)$ fixed effects $\Pi_{w, t}$ using a difference-in-difference approach. ${ }^{14}$

Our first step is to identify particular electoral wards $w$ as preferred locations for demand arising from specific countries (we denote countries by $k$ ) using our identifying assumption of "home bias abroad." A simple way to do this is to sort wards by the strength of their link to country $k$ - as mentioned, we measure this link by the share of people residing in the ward that were born in country $k$, but this could easily be generalized to any other plausible link variable. We later run a placebo test to ensure that accurate mapping of wards to specific countries is necessary for our results, and

\footnotetext{
${ }^{14}$ In our implementation of the estimation procedure, we exclude one location fixed effect and one of the location by time fixed effects for each location. In particular, we drop the first electoral ward (ordered alphabetically, this is Abbey in the UK Office for National Statistics set) and the respective first time periods $(\mathrm{Q} 1,1995)$ for each of the other wards. All fixed effects are therefore estimated relative to this ward and time period.
} 
demonstrate that this is indeed the case.

The first difference in our diff-in-diff approach is along this links dimension. We subtract $\Pi_{w, t}^{\text {low }(k)}$ (denoting the top $20 \%$ of wards with the lowest level of residents from country $k$ ) from $\Pi_{w, t}^{h i g h(k)}$ (denoting the top $20 \%$ of wards with the highest level of residents from country $k$ ), and denote this price spread as $s_{t}^{k}$ :

$$
s_{t}^{k}=\Pi_{w, t}^{h i g h(k)}-\Pi_{w, t}^{l o w(k)} .
$$

The second difference is to inspect the behaviour of the spread at times of elevated risk in source country $k$, relative to its behaviour during more normal periods. Our baseline model regresses the quarterly growth rate $\left(\Delta s_{t}^{k}\right)$ of the price spreads described in equation (2) on $z_{t}^{k}$, a risk indicator for country $k$ :

$$
\Delta s_{t}^{k}=\mu^{k}+\delta_{t}+\rho \Delta s_{t-1}^{k}+\sum_{l=1}^{L} \zeta_{l} z_{t-l}^{k}+u_{t}^{k} .
$$

To construct the risk regime indicator $z_{t}^{k}$, we adopt the following procedure. We first compute quarterly changes in political risk for across all countries and all periods, and then weight these changes by the prevailing absolute levels of risk. So for example if, say, for Russia, the underlying political risk measure moves from a value of 4 to a value of 6 in a particular quarter, the cardinal number we compute for this country quarter is $(6-4) * 6=12$. $z_{t}^{k}$ is then a dummy variable which takes the value of one for each such observation that lies above the $90^{\text {th }}$ percentile of the distribution of this variable, i.e., picking the top $10^{\text {th }}$ percentile of such events. Using this procedure, we generate 19 risk events in Iraq, 14 in Russia, 10 in Egypt, one in Germany (Q4, 2009), and zero in Sweden over our sample period, which accords with casual intuition about the risk events that we pick out from the data. ${ }^{15}$ During estimation, we lag $z_{t}^{k}$ to allow for the possibility that economic and political conditions may build up over a period of time. In this sense, our approach is predictive rather than purely explanatory. In our benchmark specification, we use a maximum lag of $L=20$ quarters, to balance precision in estimation against the need to capture the substantial delays in housing transactions (owing to information acquisition, legal processes, or the international transfer of funds, for example) initiated by overseas investors.

\footnotetext{
${ }^{15}$ In earlier versions of the paper available online, we show that this construction is sensible the effects of $z_{t}^{k}$ are large and statistically significant only when $z_{t}^{k}$ is in its top few deciles. We also estimated linear specifications in which we did not transform these variables, with very similar results. The current specification captures the impact of high movements in country-risk on locations in London with a high foreign share, permitting sharper identification.
} 
A few aspects of equation (3) are worth describing here. First, this specification permits causal inference about the effect of foreign demand on London house prices, under the plausible assumption that there is no reverse causality possible from intra-London variation in house prices to aggregate foreign risk variation. This is an advantage of the approach, as it permits relatively clean inferences about causal effects.

Second, we include time fixed effects $\delta_{t}$ in the specification. We are interested in the specific effect of political risk in particular countries on the price spread between areas with high vs. low shares of people born in those countries. We include time fixed effects in an attempt to draw inferences from specific events rather than claiming credit for inferences drawn from political risk shocks that affect many countries simultaneously. Another useful feature of the time fixed effects is that they eliminate any concern that our effects are driven by common price developments in areas that may be particularly attractive for foreigners (i.e., to the extent that there is not perfect geographic separation within London of residents from different countries), for example because they offer more standardized accommodation (studios, apartments or maisonettes), or easier access to certain (unobservable and observable) amenities favoured by foreigners (such as pre-existing historical links or friendships, international restaurants, or international schools).

Third, our dependent variable is the quarterly change in the price spread $\Delta s_{t}^{k}$. This is to control for the effect of persistence in cross-ward price spreads on our inferences, which we also do by including the lag of the dependent variable $\left(\Delta s_{t}^{k}\right)$ as an explanatory variable. ${ }^{16}$ In addition, we employ double clustered standard errors at the country and year level, which correct for both cross-sectional correlation and time series dependence in the residuals (see Cameron et al 2011). ${ }^{17}$

Fourth, we write the specification to include country-specific fixed effects $\mu^{k}$. In this way, we control for the possibility that there may be constant cross-ward price differentials for all wards associated with each country $k$, i.e., our specifications do not allow such persistent differentials to affect our estimation of safe-haven effects.

Fifth, in equation (3), the coefficients $\zeta_{l}$ measure the impact of foreign demand on London house prices. We expect $\zeta_{l}>0$ if foreign risk drives capital flows towards London locations which are linked to these countries, generating price impact in London house prices. Our specification simply constrains the effects to be the same across all countries $k$ to begin with, though we explore which world regions are associated with

\footnotetext{
${ }^{16}$ We thank Philipp Schnabl for suggesting that we adequately control for the persistence of crossward price spreads.

${ }^{17}$ In the online appendix, we show that our results are robust to double clustering at the level of world regions and years.
} 
the maximum impact on London house prices later in the paper.

In terms of coefficient magnitudes, our specification implies that $l$ periods after a risk shock occurs in country $k$, there will be an additional house price premium of $\zeta_{l}$ on transactions that take place in a ward with a high share of people born in country $k$. To facilitate easy interpretation of the magnitude of the estimated effects at different horizons, in all tables and figures we report cumulative impulse responses up to a maximum horizon of $h=20$ quarters, as implied by equation (3), i.e.:

$$
E\left[s_{h}^{k} \mid z_{0}^{k}=1, s_{0}^{k}=0\right]=\sum_{l=1}^{h}\left(\sum_{j=0}^{h-l} \rho^{j}\right) \zeta_{l} .
$$

We then multiply the estimated magnitudes by 100, so that they can be interpreted as accumulated percentage point changes in the house price spreads, and assess the statistical significance of the accumulated impulse responses through non-linear F-tests.

A convenient null hypothesis in this regression is that increases in foreign risk in country $k$ have no effect on the price spreads between London wards with high and low shares of population from country $k$. It is also possible of course that we find negative responses. This could happen, for example, if declines in risk are associated with increases in prosperity, leading to an interpretation as a wealth effect. High political risk in particular countries could also be accompanied by the imposition of capital controls or other restrictions on the ability of country residents to move capital overseas at such times, and a consequent reduction in capital flows to their preferred London areas, leading to a negative coefficient. However, we rarely find such negative responses in our empirical results and they are never statistically significant. ${ }^{18}$

Finally, we note that identifying cross-country variation in the strength of foreign demand effects is difficult, as people from different countries which are geographically close to one another also tend to cluster around specific areas. We are able to identify broader regional effects, however. As we show in Figure 3, the data show that there is substantial cross-sectional heterogeneity when countries are grouped into broader regions of the world. We exploit this heterogeneity to isolate the different magnitudes of safe-haven effects arising from different regions of the world, computing cumulative impulse responses based on the estimated coefficients $\rho$ and $\zeta_{l}^{r e g i o n}$ from the following

\footnotetext{
${ }^{18}$ An earlier version of this paper did estimate negative and statistically significant coefficients in some cases. We attribute this to three sources. First, an imperfect control for ward-level characteristics, which appear to have been cleaned up by the additional differencing of high- $k$ and low- $k$ wards. Second, we adjust our standard errors more aggressively (thanks to Stefano Giglio for this suggestion), leading to an attenuation in statistical significance especially for the negative coefficients. Third, the use of top-decile indicators for risk permits cleaner inferences about specific risk "events".
} 
specification:

$$
\Delta s_{t}^{k}=\mu^{k}+\delta_{t}+\rho \Delta s_{t-1}^{k}+\sum_{l=1}^{L} \zeta_{l}^{r e g i o n} z_{t-l}^{k}+u_{t}^{k}
$$

where the coefficients $\zeta_{l}^{\text {region }}$ are allowed to vary across the set of eight world regions. We also use equation (5) to quantify the overall contribution of foreign demand effects to the changes in house price spreads.

In the next section, we describe our approach to understanding the underlying economic determinants of our estimated safe haven effects.

\section{E. Interpreting the Estimates}

Our estimates of the impact of foreign demand on the London housing market rely on (a) higher risk in the country of origin being associated with greater capital outflows, (b) the London market being a destination of these outbound flows, and (c) the spatial allocation of country-specific capital flows in London being directed towards areas with a high share of foreign-born people from the specific country. The cross-region variation in coefficients will mirror the extent to which one or all of these identifying assumptions are satisfied.

Perhaps more substantively from an economic rather than a purely statistical point of view, there are at least three ways in which the additional demand related to the realization of a foreign risk shock can affect residential purchase decisions in the London real estate market. First, foreigners facing economic and political risk in their home countries can simply transfer capital to a market perceived as a safe haven, for pure capital preservation motives. This type of cross-border transaction has been widely discussed, often with an associated negative connotation (see Transparency International 2015). Second, any disruptions arising from increases in government instability and conflict will ultimately translate into cross-border migration by foreigners, with the associated demand for housing in the destination country. Third, pre-existing UK residents born in foreign countries could "retrench" capital located overseas, either by transferring resources from their country of origin or simply by reducing remittance flows towards those countries (see, for example, Stark and Lucas, 1988). ${ }^{19}$

To dig deeper into the sources of our estimated effects, we estimate the following

\footnotetext{
${ }^{19}$ Such remittances or retrenchments often materialize almost immediately after the shock is realized. The World Bank (2015) estimates that countries such as India, Nigeria, Bangladesh, Somalia, Kenya and Ghana (all of which have high levels of local political risk) are among the largest destinations for remittances from the UK. Interestingly, most senders are long-term residents and have British nationality: for example, $71 \%$ for Somalia and $69 \%$ for Bangladesh.
} 
specification, which modifies (3) to include an additional interaction variable $F^{k}$ :

$$
\Delta s_{t}^{k}=\mu^{k}+\delta_{t}+\rho \Delta s_{t-1}^{k}+\sum_{l=1}^{L}\left(\zeta_{l}+\sum_{j=1}^{4} \xi_{j, l} F_{j}^{k}\right) z_{t-l}^{k}+u_{t}^{k}
$$

We propose four such variables $F^{k}$. The first, $F_{1}^{k}$, is the standard deviation of foreign-born shares across wards, normalized by the average foreign-born share. This is essentially a measure of population concentration - a high value indicates that the respective population has a relatively larger tendency to cluster around specific areas. The second, $F_{2}^{k}$, is the average value of political risk for each country in the sample, calculated using the entire available time series between 1995 and 2013. The third, $F_{3}^{k}$, is the contribution of each country to the overall amount of capital flows entering the London commercial property market. Finally, $F_{4}^{k}$ is the relative contribution of each country to the overall flow of migrants into London over our sample period. ${ }^{20}$

We compute impulse responses based on the estimated coefficients $\rho, \zeta_{l}$, and $\xi_{j, l}$ for different horizons. To facilitate interpretation about this specification, note that the marginal effect of a shock to political risk in country $k$ estimated in equation (6) is the sum of two components. The first component is common across all countries, while the second component is specific to shocks originating in country $k$, and implied by the degree to which country $k$ is special along each of the four dimensions $F_{1}^{k}, \ldots, F_{4}^{k}$.

The results from this specification allow us to understand whether the estimated magnitude of foreign-demand effects is driven by (a) the varying statistical power properties of our identification method, as reflected in the concentration of the foreign-born population, (b) the strength of the capital flight motive and the transfer of resources towards the UK associated with a higher level of political risk in the country of origin, (c) the broad amount of capital flow entering the London commercial property market, which is the cleanest available measure of aggregate country-specific capital flows to real estate that we have available, and (d) the patterns of immigration into the city of London.

\section{F. Foreign Demand Effects and Transaction Volumes}

Finally, to complement the evidence obtained from prices, we investigate whether the foreign uncertainty measures and our identification strategy are related to London

\footnotetext{
${ }^{20}$ For easier interpretation of the estimated coefficient magnitudes, we divide the country-specific average levels of risk by the overall average level of risk across all countries. Because of limited data availability in the construction of the two latter variables, we also use region-level averages for each country in a given region.
} 
housing market transaction volumes.

Many authors, such as Stein (1995), and Ortalo-Magne and Rady (2006), have shown that aggregate transactions volumes are positively associated with prices. Stein (1993) presents a rational model in which he explains this association with the fact that price increases and declines affect available downpayment amounts for mortgageholders, and hence, the ability of homeowners to move. Genesove and Mayer (2001) rationalize the observation using loss aversion of prospective sellers.

If our approach is able to capture safe-haven cross-border housing transactions in London, we should observe at least a temporary increase in housing market activity in response to the foreign risk shock. Therefore we also check whether our method allows us to predict the variation in housing market transactions across wards. To do so, we first take the transactions volume $V_{w, t}$ in each ward $w$ and quarter $t$, and use these variables to construct volume spreads between the top $20 \%$ of wards with the highest level of residents from country $k$ and the bottom $20 \%$ of wards with the lowest level of residents from country $k$. The volume spread is denoted as $\nu_{t}^{k}$ :

$$
\nu_{t}^{k}=\frac{V_{w, t}^{h i g h(k)}-V_{w, t}^{l o w(k)}}{V_{w, t}^{l o w(k)}},
$$

We then estimate the following specification, analogous to equation (3):

$$
\Delta \nu_{t}^{k}=\omega^{k}+\tau_{t}+\gamma \Delta \nu_{t-1}^{k}+\sum_{l=1}^{L} \eta_{l} z_{t-l}^{k}+\epsilon_{t}^{k}
$$

where the change in the relative spread in transaction volumes $\left(\Delta \nu_{t}^{k}\right)$ is explained by the past history of foreign risk $\left(z_{t-l}^{k}\right)$, controlling for ward fixed effects $\left(\omega^{k}\right)$ and eliminating any confounding influence of the global component of risk through time fixed effects $\left(\tau_{t}\right)$.

Based on the estimated coefficients $\eta_{l}$, we construct cumulative impulse responses up to a horizon of $h=20$ quarters:

$$
E\left[\nu_{h}^{k} \mid z_{0}^{k}=1, \nu_{0}^{k}=0\right]=\sum_{l=1}^{h}\left(\sum_{j=0}^{h-l} \gamma^{j}\right) \eta_{l} .
$$

Under the null hypothesis, the average impulse response of the spread in transaction volumes to a foreign risk shock will not be different from zero. Under the alternative, positive values document relatively more intense market activity in areas with stronger international ties conditional on a foreign risk shock. 
Analogous to the specification with which we explain house price spreads, we also allow for regional variation in the magnitude of foreign demand effects on cross-ward spreads in terms of transaction volumes:

$$
\Delta \nu_{t}^{k}=\omega^{k}+\tau_{t}+\gamma \Delta \nu_{t-1}^{k}+\sum_{l=1}^{L} \eta_{l}^{r e g i o n} z_{t-l}^{k}+\epsilon_{t}^{k}
$$

and construct impulse responses for each world region separately, based on estimated coefficients $\eta_{l}^{\text {region }}$.

\section{Data}

We employ a number of datasets in our study. We use two micro-level databases of housing transactions in the UK, from the UK Land Registry, and from the Nationwide Building Society; a database of cross-border commercial property transactions; and a property-level dataset of ownership records. We use census data from the Office for National Statistics in the UK to identify the country of origin of London residents, registrations for National Insurance in London, and immigration statistics. Finally, we use time-series indexes of country-level economic and political risk measures from the PRS Group (International Country Risk Guide), and the Polity IV Project.

\section{A. Registry Data}

We obtain data on the complete set of house purchases in London from HM Land Registry. All purchasers of houses are required to report transactions to the Land Registry, and the data cover 2,440,618 transactions over the period from 1995 to 2013. This constitutes $13 \%$ of roughly 19 million residential property sales the Land Registry has lodged for the whole of England and Wales, with a few property characteristics including the type of house (e.g., whether it is an apartment), the tenure status (leasehold or freehold) and an indicator for new builds.

The Land Registry provides a postcode for each traded property. In the UK, postcodes allow for very granular geographical identification of properties, often covering just a segment of a street. This allows us to link each property to London electoralward-level information allowing us to control for price-relevant characteristics of the location in which each property is located, and most importantly for our purposes, allowing us to connect property prices with the share of foreign residents, and the income level in each electoral ward. 
Table 2

Summary statistics

The table reports selected statistics which capture the distribution of observed prices and volumes, for both the transaction-level data from the Land Registry and the loan-level data from the Nationwide Building Society. A hyphen indicates that our data samples do not cover the respective years.

\begin{tabular}{|c|c|c|c|c|c|c|c|c|c|c|}
\hline \multirow[b]{3}{*}{ Year } & \multicolumn{5}{|c|}{ Registry dataset } & \multicolumn{5}{|c|}{ Loans dataset } \\
\hline & \multicolumn{4}{|c|}{ Transaction prices (in £'000) } & \multirow{2}{*}{$\begin{array}{c}\text { Transaction } \\
\text { volume }\end{array}$} & \multicolumn{4}{|c|}{ Transaction prices (in $£^{\prime} 000$ ) } & \multirow{2}{*}{$\begin{array}{c}\text { Transaction } \\
\text { volume }\end{array}$} \\
\hline & Min & Mean & Max & St. dev. & & Min & Mean & Max & St. dev. & \\
\hline 1995 & 14.0 & 113.6 & $3,750.0$ & 107.7 & 84,592 & - & - & - & - & - \\
\hline 1996 & 12.5 & 120.6 & $8,000.0$ & 120.6 & 108,825 & 10.5 & 84.6 & $1,000.0$ & 51.7 & 12,243 \\
\hline 1997 & 28.0 & 132.8 & $7,500.0$ & 139.1 & 133,694 & 17.5 & 97.4 & 920.0 & 57.6 & 13,108 \\
\hline 1998 & 26.5 & 143.6 & $11,300.0$ & 163.1 & 133,859 & 21.0 & 118.6 & 935.0 & 71.6 & 12,463 \\
\hline 1999 & 28.0 & 163.1 & $32,500.0$ & 190.9 & 163,034 & 24.0 & 135.4 & 980.0 & 77.3 & 19,330 \\
\hline 2000 & 30.0 & 190.7 & $10,000.0$ & 214.1 & 147,960 & 28.5 & 149.8 & 960.0 & 82.8 & 8,958 \\
\hline 2001 & 48.5 & 205.7 & $24,800.0$ & 222.7 & 162,788 & 35.0 & 169.8 & 971.0 & 89.3 & 7,522 \\
\hline 2002 & 50.2 & 234.0 & $8,300.0$ & 217.9 & 174,769 & 42.5 & 197.9 & 998.0 & 92.6 & 9,386 \\
\hline 2003 & 50.3 & 250.8 & $9,250.0$ & 219.4 & 151,842 & 57.2 & 221.3 & 950.0 & 94.6 & 7,371 \\
\hline 2004 & 52.0 & 274.6 & $7,950.0$ & 238.4 & 160,084 & 65.0 & 243.9 & $3,340.0$ & 106.0 & 7,565 \\
\hline 2005 & 52.0 & 289.9 & $15,200.0$ & 266.6 & 137,732 & 83.0 & 256.4 & $1,955.0$ & 108.3 & 6,649 \\
\hline 2006 & 50.8 & 315.5 & $12,400.0$ & 305.6 & 172,462 & 48.1 & 273.9 & $3,125.0$ & 132.4 & 10,712 \\
\hline 2007 & 52.5 & 352.3 & $17,000.0$ & 358.8 & 166,508 & 68.0 & 312.8 & $2,500.0$ & 154.1 & 9,143 \\
\hline 2008 & 51.0 & 360.7 & $19,800.0$ & 423.9 & 81,736 & 94.5 & 297.6 & $1,625.0$ & 149.4 & 3,977 \\
\hline 2009 & 50.0 & 361.3 & $12,500.0$ & 385.9 & 75,455 & 70.0 & 294.2 & $1,850.0$ & 148.4 & 4,394 \\
\hline 2010 & 51.0 & 406.0 & $16,200.0$ & 466.0 & 91,940 & 50.0 & 320.0 & $1,850.0$ & 172.0 & 5,068 \\
\hline 2011 & 50.8 & 418.9 & $21,000.0$ & 497.6 & 89,841 & 81.0 & 347.5 & $4,400.0$ & 205.5 & 6,356 \\
\hline 2012 & 50.5 & 435.8 & $55,000.0$ & 625.1 & 92,267 & 66.5 & 321.2 & $2,550.0$ & 171.6 & 9,892 \\
\hline 2013 & 10.0 & 473.9 & $39,000.0$ & 635.4 & 111,230 & - & - & - & - & - \\
\hline Full sample & 10.0 & 265.7 & $55,000.0$ & 337.0 & $2,440,618$ & 10.5 & 203.3 & $4,400.0$ & 142.4 & 154,137 \\
\hline
\end{tabular}


Table 2 describes the distribution of transaction volumes and prices in the data. The number of housing transactions dips in 2008 and remains low relative to historical averages during the credit crisis. Over the same period, however, average house prices increase. More generally, transaction volumes appear much more volatile than prices, especially for more granular geographic units such as wards. This leads to a number of outliers in the distribution of quarterly changes in volume spreads.

In our empirical implementation of the cross-country analysis in equation (7), we therefore trim the top and bottom $5 \%$ of this distribution. This reduces the noise in the data, while the estimated magnitudes of coefficients and accumulated impulse responses are not affected.

The Registry dataset does not contain information about the provenance of buyers. We note that these data are likely to miss extremely highly-priced properties in premium areas of London, because of a higher tendency of these types of properties to be classified as commercial real estate and to be purchased using private trusts or specialized companies. Nevertheless, we still find that during the years characterized by large political crises around the world (1998 in Russia, 2001 in South- and Central America and 2012-2013 in the Middle East, Russia, and Europe), residential transactions in the Registry data include exceptionally expensive houses. For example, the overall most expensive residential property in London was sold for $£ 55$ million in 2012 . In contrast, the distribution of transaction prices is less disperse during periods of relative calm, such as 2003 and 2004. ${ }^{21}$ This is reassuring, as it suggests that these data are able to capture some part of the demand of wealthy (foreign and local) private investors in the London housing market.

\section{B. Loan-Level Data}

To check our results using the Registry data, we employ proprietary loan-level mortgage data covering the period 1996 to 2012, obtained from the Nationwide Building Society. Nationwide is the second largest mortgage lender in the UK, with a market share of $14.8 \%$ of gross lending in 2012, and their house price index is considered one of the benchmark indexes characterizing the evolution of the UK housing market. These data are collected following the completion of valuation reports on properties serving as mortgage collateral, and cover 154,137 observations of house purchases widely spread across London electoral wards over the sample period. This amounts to $11 \%$ of the

\footnotetext{
${ }^{21}$ Market-level evidence collected by private agencies in London tends to support this hypothesis. For example, the estate agency Savills (Market Research Report, "The World in London") estimates that around $20 \%$ of low-end newly built properties were bought by foreigners in 2013. This number rises gradually for more expensive properties, and reaches $90 \%$ for luxury units.
} 
roughly 1.4 million transactions which are reported by Nationwide for the entire UK since 1996.

Despite its substantially smaller size, we use Nationwide data for two main reasons. First, the Nationwide data allow us to better control for a wider set of property-specific hedonic characteristics than the Registry data, serving as a robustness check to our main analysis. ${ }^{22}$ Second, the Nationwide data are far more likely associated with domestic residents than with foreign demand. If we find effects of foreign demand on transactions prices in these data as well, they are informative about the extent to which price impacts of foreign demand spill over into the domestic housing market.

In Table 2, we show that the average price is equal to $£ 265,700$ across all properties lodged with the Land Registry and $£ 203,300$ for the ones which are subject to a mortgage loan from Nationwide. This is due to marked differences at the top of the distribution. The most expensive property used as collateral in the Nationwide data has a value of $£ 4.4$ million, which lies an order of magnitude below the most expensive residential property sold in London over the sample period ( 555 million).

\section{UK Office for National Statistics (ONS)}

We implement the majority of our analysis at the level of electoral wards. The 624 wards in London function as political sub-divisions, but also as administrative entities within the city. The average number of people residing in each ward is roughly 13,000. We identify properties with wards using property postcodes and the ONS postcode directory. There are 1.8 million postcodes active in the UK, corresponding to 29 million postal addresses, an average of roughly 16 buildings per postcode. For each individual housing transaction from both Nationwide and Land Registry samples, we match postcodes to wards, and acquire demographic and geographical characteristics associated with the location of the house, also available from the ONS.

Data from the ONS on the composition of electoral wards is available in years 2001 and 2011, and we use data from 2001 throughout our study to identify ward-level characteristics. A key variable in our analysis is the share of each ward's population that was born in foreign countries $k$. To select the $k \in K$ countries which we employ in our analysis, we do not impose any a priori criteria. Instead, we consider the entire set of countries represented in London. We distinguish between high- and low-risk countries, based on average levels of political risk. We choose a cut-off value for the ICRG index

\footnotetext{
${ }^{22}$ For each individual property in the Nationwide London sample, in addition to the loan approval date and the purchase price, we know the geographical location at postcode level, the tenure status, the house type, the year of construction, the floor area, the number of bathrooms, bedrooms, and garages, and whether the borrower is a first-time home buyer.
} 
of 18.1 (Japan), which corresponds to the bottom $25 \%$ of the distribution of countries in our sample. ${ }^{23}$ These 13 relatively wealthy and low-risk countries in our sample are Japan, Belgium, the US, Germany, Singapore, Australia, Canada, Austria, Denmark, New Zealand, the Netherlands, Sweden, and Finland. The remainder of the countries in the sample, reported in Table 3, are classified as higher-risk. ${ }^{24}$ We implement our analysis in the sample of high-risk countries and use the low-risk sample as a useful placebo test.

When estimating effects emanating from specific parts of the world, we aggregate the data into eight world regions: Southern Europe, Eastern Europe, Russia, the Middle East, Africa, South Asia, Asia-Pacific, and South and Central America. ${ }^{25}$

The online appendix shows histograms of a number of other ward-level variables. It does seem that wards more densely inhabited by people of foreign origin have important differences with the remainder, but such time-invariant characteristics of wards are not allowed to affect our estimation, as we include country-specific fixed effects in our specification to absorb static cross-ward differences in price spreads. We observe that the fraction of owners with mortgages appears to be lower in wards with high shares of foreign-born people. While it is of course possible that foreigners' access to the UK mortgage system is less straightforward than access for UK-born London residents, we see this fact as consistent with the argument that foreign-origin people draw upon sources of funds which lie outside the UK mortgage system, and at least partially, may come from overseas.

Panel A of Figure 3 shows the correlation between the shares of people born in different regions of the world (darker shaded areas of the matrix represent higher correlations), and confirms that London residents that were born abroad tend to locate around areas that are different from the areas preferred by UK-born residents.

\footnotetext{
${ }^{23}$ In the online appendix, we show that political risk increases abruptly to 21.5 for the Czech Republic and Poland, the countries immediately above Japan.

${ }^{24}$ According to the ICRG indicators, Portugal has, on average, a low level of risk across the entire sample period. However we exercise judgment here and include Portugal in the list of higher-risk countries given its recent crisis. Our results are not affected by this reclassification. Similarly, we have decided to keep France in our sample of high-risk countries, given the recent evidence of capital flight towards the UK, directly associated with the increase in fiscal policy uncertainty. In the online appendix, we show that our results are robust to this choice.

${ }^{25}$ We aggregate country-level variables into regions by weighting individual country data by the extent to which these countries are represented in London's population. The ONS does not report country-specific population shares for some of the countries in our sample, so we simply use the overall share of people born in the Middle East for Qatar, UAE, Saudi Arabia, Syria, Lebanon, and Israel; the shares of people born in North Africa for Tunisia, Egypt, Algeria, and Libya, and the shares of people born in South America for Argentina, Brazil, Chile, and Mexico. In our benchmark regression, we consider a single average measure of risk and a single average spread for the country groups for which the foreign-born shares are imputed in this way.
} 
Table 3

List of countries and world regions

The table reports the list of countries used in our analysis on the effects of external factors on the London housing market. We consider countries with relatively higher average levels of political risk, based on the composite political risk index from the PRS Group's International Country Risk Guide.

\begin{tabular}{|c|c|c|c|c|c|}
\hline \multicolumn{3}{|c|}{ Southern Europe } & \multicolumn{3}{|l|}{ Africa } \\
\hline Italy & Spain & Portugal & Nigeria & Sierra Leone & Somalia \\
\hline France & Greece & & Kenya & South Africa & Libya \\
\hline \multicolumn{3}{|c|}{ Eastern Europe } & Zimbabwe & Tunisia & Egypt \\
\hline Poland & Romania & Czech Rep. & Algeria & & \\
\hline \multicolumn{3}{|l|}{ Russia } & \multicolumn{3}{|c|}{ Middle East } \\
\hline \multicolumn{3}{|c|}{ Asia-Pacific } & Cyprus & Turkey & Iran \\
\hline China & Hong Kong & Japan & Iraq & Qatar & Lebanon \\
\hline \multicolumn{3}{|l|}{ Malaysia } & S. Arabia & $\mathrm{UAE}$ & Israel \\
\hline \multicolumn{3}{|c|}{ South-Asia } & \multicolumn{3}{|l|}{ Syria } \\
\hline India & Bangladesh & Pakistan & \multicolumn{3}{|c|}{ South- and Central America } \\
\hline \multirow{2}{*}{\multicolumn{3}{|c|}{ Sri Lanka }} & Jamaica & Brazil & Argentina \\
\hline & & & Chile & Mexico & \\
\hline
\end{tabular}




\section{Figure 3}

Shares of foreign-born people and foreign political risk

In Panel A, we report the pairwise correlation coefficients between the shares of people born in foreign countries, across the 624 London wards. Blocks in darker shading indicate a higher tendency of the population from the respective regions to cluster around similar areas of the city. We calculate the fractions of foreign-born people relative to the total ward population by using 2001 census data. In Panel B, we report the time-series evolution of average political risk in the eight world regions.

\section{Panel A}

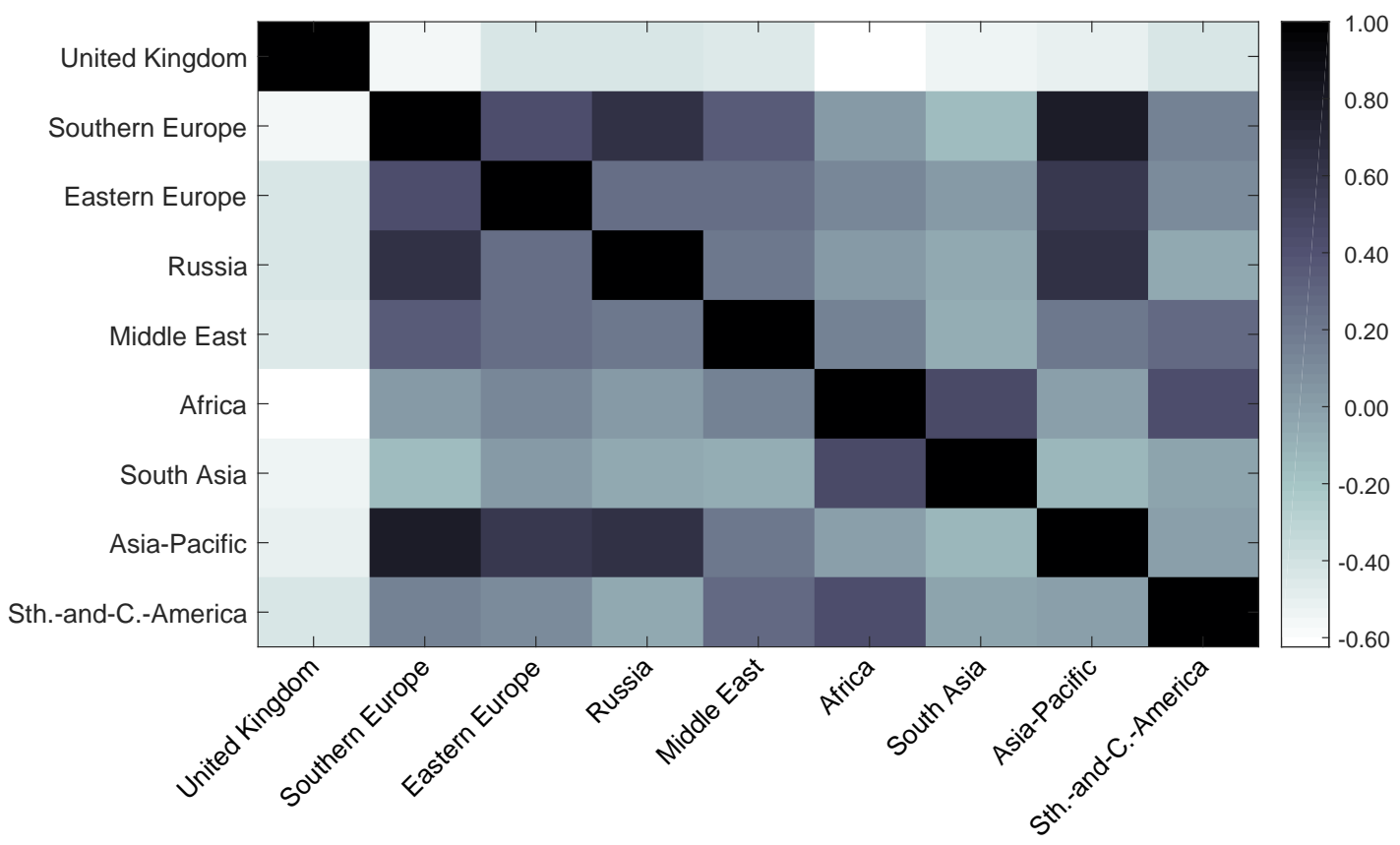

Panel B

\section{ICRG risk indicators}

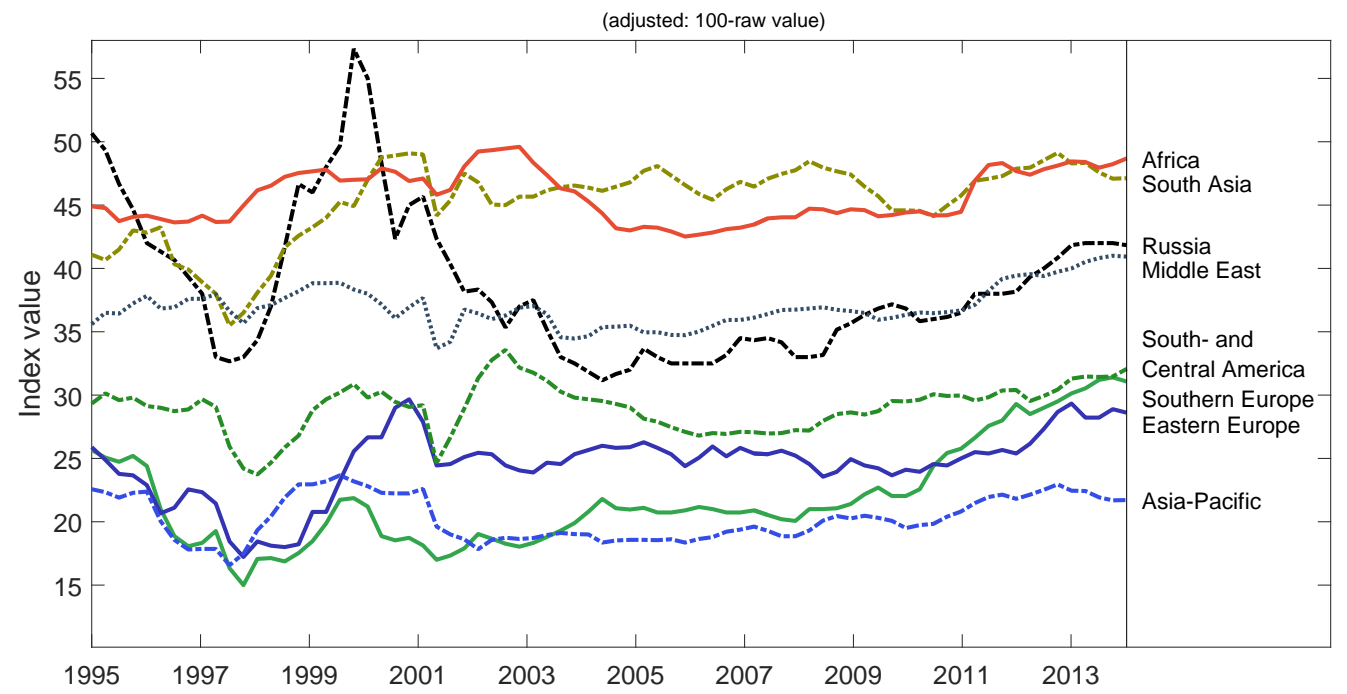


Since people that come from culturally and geographically proximate countries tend to live near one another, this location choice also means that we will find it difficult to estimate country-specific effects - as a result, we group countries into regions when we attempt to estimate the more specific origins of foreign demand effects.

We note that there is significant variation in location choices by residents originating from different regions of the world.

\section{Measures of Foreign Risk}

We measure economic and political risk in foreign countries each quarter using three separate variables. First, in the majority of our analysis we use the International Country Risk Guide (ICRG) indexes of political risk. These indexes rate each country each month along 12 dimensions, each of which contributes to the total country rating according to the number of points indicated in parentheses: government stability (12 points), socioeconomic conditions (12 points), investment opportunities (12 points), the potential for internal and external conflicts (24 points), the level of corruption (6 points), the influence of military in politics (6 points), the prevalence of religious tensions (6 points), general conditions in terms of law and order (6 points), ethnic tensions (6 points), democratic accountability (6 points), and the quality of bureaucracy (4 points). For each country, we build a composite index by simply summing across these 12 risk categories (by ICRG construction, this adds up to 100). ${ }^{26},{ }^{27}$

Glaeser et al. (2004) note that the ICRG indicators do not perfectly describe the permanent state of country-level political institutions, but instead reflect changes in these institutions over time. This is well-suited to our purposes, as we are most interested in capturing changes in the political situation in a given country, rather than static differences across institutions. These authors also emphasize that the ICRG indicators are subjective assessments of risk, which we also find desirable, as we are interested in sentiment about the local political environment driving capital flight.

The ICRG data are also used by Erb, Harvey, and Viskanta (1996 a,b), who show that ICRG ratings are correlated with expected stock and bond returns in a variety of countries. Moreover, work on international capital flows finds that there is a strong relationship between risk and institutional quality in source countries, and their extent

\footnotetext{
${ }^{26}$ As constructed, the index ranges from 0 to 100 , with 0 indicating the highest possible risk. In our empirical implementation, we simply replace this with 100 minus the original values so that high levels of the index indicate high levels of risk and vice versa.

${ }^{27}$ In the online appendix, we show that changes in risk are driven mostly by factors related to the stability of the government, internal and external conflicts, and the investment profile. These components of risk are also the ones contributing to positive safe-haven effects, in particular the likelihood of internal and external conflicts, the investment profile, and the role of religion in politics.
} 
of outbound direct and portfolio investment (see, for example, Alfaro et al. 2008, and Forbes and Warnock 2011).

Panel B of Figure 3 plots the evolution of the ICRG measures in the eight regions of the world that we study. The plot shows that these measures capture major political events and periods of widespread turmoil. Our sample period includes the Russian political crisis of 1999, the South-American crises around the turn of the millennium, the outbreak of the Arab Spring at the end of 2010, as well as the gradual increase in political uncertainty in Southern Europe in the wake of the 2009 sovereign debt crisis.

Finally, we check the robustness of our results using the Combined Polity IV index. The data are available at an annual frequency, for the entire sample period between 1995 and 2013. Compared to the ICRG risk index, Polity IV focuses on the strength of democratic institutions and is widely used to capture transitions between political regimes (see, for example, Rodrik and Wacziarg, 2005, and Tabellini, 2010).

\section{E. Capital Flows and Migration}

To better gauge the economic mechanisms driving our results, we draw upon additional micro-level datasets, as well as a disaggregated time series of migration flow. The first micro-dataset is provided by the UK Land Registry and covers the complete set of residential properties in London which are registered to foreign-owned companies. The data excludes private individuals, UK companies with an overseas address, and charities. For each record, we know the location of the property and the country of residence of the primary owner. The reference period for ownership records is 31 October 2015. Since the Land Registry does not publish historical vintages of these data, we are not able to use the data to trace changes in ownership through time.

The second dataset covers representative commercial property transactions in London between 2005 and 2013, for deals with a value of $£ 2$ million or above. The data cover around $85 \%$ of the commercial property market in London. For each record, we know the transaction price and the country in which the buyer is registered. This allows us to compute total capital inflows into the commercial property market, as well as relative shares for each of country and world region in our sample.

Finally, we obtain the numbers of registrations for National Insurance in London from the Department for Work and Pensions, as well as the numbers of visas granted to foreign citizens during the period between 2008 and 2013 from the UK Border Agency, in particular Tier 1 (Investor) visas. Tier 1 visas are granted to foreign investors investing more than $£ 2$ million in UK government bonds, share capital, or loan capital in active registered companies. 
In order to obtain an investor visa, foreign nationals have to prove their ability to invest capital in the country. The visas are initially granted for a period of three years, so they are likely to be associated with a significant medium- to long-term capital inflow. We next turn to describing the results from our estimation, beginning with the estimated hedonic characteristics from equation (1).

\section{Results}

\section{A. Hedonics}

Table 4 shows the coefficients $\beta$ from a simple hedonic regression specification to explain London house prices, which includes time- and ward- fixed effects. Panel A of the table shows the estimated coefficients on the hedonic characteristics that are common to both Land Registry and Nationwide datasets, with the left (right) part of the panel showing the estimated effects in the former (latter) dataset. While the Land Registry data is somewhat sparse on hedonic characteristics, the estimated signs for the common characteristics are strongly consistent across the datasets. Panel B of the table shows the set of hedonic characteristics that are present only in the Nationwide data.

The estimated contributions to marginal hedonic utility of bedrooms, bathrooms, parking spaces, and floor area (the omitted category is the smallest possible unit in all cases) appear very reasonable. Older properties, all else equal, are valued higher than newer ones (with the exception of properties built in the 2000s which are not new builds), and detached houses are worth more than any other category of houses, once floor-space area is controlled for. ${ }^{28}$

\section{B. Estimated Foreign Demand Effects}

Table 5 summarizes the findings from estimating equation (3). The first column presents estimated impulse responses from conditioning the panel of spreads on lagged values of high-risk dummies computed using ICRG indexes for each country. The results from this specification using the Registry dataset show that high levels of risk in country $k$ precede higher price growth in wards with high shares of country $k$ residents.

\footnotetext{
${ }^{28}$ Our empirical specifications focus on interactions between ward-level characteristics and foreign risk; we do not consider how safe-haven demand may be associated with particular property-level hedonic characteristics. It is of course straightforward to extend our approach to account for these possibilities. As a further robustness exercise (available in the online appendix), we have interacted property characteristics with ward-level fixed effects and computed house price spreads by using the residual ward cross time component. All our results are unaffected by this transformation.
} 
Table 4

Estimated coefficients in the hedonic regression framework

The table reports estimated coefficients from the following hedonic regression:

$$
\ln P_{i, t}=\alpha+\phi_{w}+\Pi_{w, t}+\beta \boldsymbol{X}_{i, t}+u_{i, t}
$$

where $\boldsymbol{X}_{i, t}$ are property-level characteristics. The reference property is a detached house which is not the first house purchase of the buyer, with freehold tenure, one bedroom, construction date before 1900 and a floor area below $50 \mathrm{~m}^{2}$. The standard errors are White heteroskedasticity-robust. *, **, *** denote statistical significance at the $10 \%, 5 \%$, and $1 \%$ level, respectively.

Panel A

\section{Registry dataset}

\begin{tabular}{ll}
\hline Semi detached house & $-0.426^{* * *}$ \\
Terraced house & $-0.580^{* * *}$ \\
Flat & $-0.744^{* * *}$ \\
\hline
\end{tabular}

\begin{tabular}{lr}
\hline New property & $0.232^{* * *}$ \\
Leasehold indicator & $-0.257^{* * *}$ \\
\hline
\end{tabular}

\begin{tabular}{lc}
\hline Semi detached house & $-0.141^{* * *}$ \\
Terraced house & $-0.191^{* * *}$ \\
Detached bungalow & 0.012 \\
Semi detached bungalow & $-0.065^{* * *}$ \\
Purpose built flat & $-0.232^{* * *}$ \\
Purpose built maisonette & $-0.274^{* * *}$ \\
Flat conversion & $-0.178^{* * *}$ \\
Maisonette conversion & $-0.208^{* * *}$ \\
\hline New property & $0.117^{* * *}$ \\
Leasehold indicator & $-0.115^{* * *}$ \\
\hline
\end{tabular}

Panel B

\section{Loans dataset}

\begin{tabular}{lc}
\hline First purchase & $-0.056^{* * *}$ \\
\hline Two bedrooms & $0.173^{* * *}$ \\
Three bedrooms & $0.229^{* * *}$ \\
Four or five bedrooms & $0.277^{* * *}$ \\
More than five bedrooms & $0.377^{* * *}$ \\
\hline Two bathrooms & $0.057^{* * *}$ \\
Three bathrooms & $0.024^{* * *}$ \\
More bathrooms & -0.005 \\
\hline Parking space & $0.042^{* * *}$ \\
Single garage & $0.080^{* * *}$ \\
Double garage & $0.098^{* * *}$ \\
\hline
\end{tabular}

\begin{tabular}{ll}
\hline Construction date & \\
\hline 1900 to 1920 & -0.004 \\
1920 to 1940 & $-0.060^{* * *}$ \\
1940 to 1960 & $-0.133^{* * *}$ \\
1960 to 1980 & $-0.141^{* * *}$ \\
1980 to 2000 & $-0.026^{* * *}$ \\
after 2000 & 0.001 \\
\hline Floor area & \\
50 to $70 \mathrm{~m}^{2}$ & $0.112^{* * *}$ \\
70 to $90 \mathrm{~m}^{2}$ & $0.189^{* * *}$ \\
90 to $110 \mathrm{~m}^{2}$ & $0.282^{* * *}$ \\
110 to $130 \mathrm{~m}^{2}$ & $0.380^{* * *}$ \\
130 to $150 \mathrm{~m}^{2}$ & $0.471^{* * *}$ \\
150 to $170 \mathrm{~m}^{2}$ & $0.570^{* * *}$ \\
above $170 \mathrm{~m}^{2}$ & $0.738^{* * *}$ \\
\hline
\end{tabular}




\section{Table 5}

\section{Cross-country panel analysis}

The table reports estimated cumulative impulse response of cross-ward price and volume spreads to a foreign risk shock, based on the following model specifications:

$$
\Delta s_{t}^{k}=\mu^{k}+\delta_{t}+\rho \Delta s_{t-1}^{k}+\sum_{l=1}^{L} \zeta_{l} z_{t-l}^{k}+u_{t}^{k}, \quad \text { and } \Delta \nu_{t}^{k}=\omega^{k}+\tau_{t}+\gamma \Delta \nu_{t-1}^{k}+\sum_{l=1}^{L} \eta_{l} z_{t-l}^{k}+\epsilon_{t}^{k},
$$

where $z_{t}^{k}$ is an indicator variable which takes the value of one if the respective risk measure is in the high-risk regime. We report impulse responses at a horizon of 2 years ( 8 quarters). The estimated impulse responses are multiplied by 100 , for easier interpretation as percentage points. We test the statistical significance of the effects using a non-linear F-test, based on clustered standard errors at the country and year level. $*, * *, * *$ denote statistical significance at the $10 \%, 5 \%$, and $1 \%$ level respectively.

\begin{tabular}{lccccc}
\hline \multicolumn{3}{c}{ Residential } & & Transaction \\
& \multicolumn{3}{c}{ property prices } & & volumes \\
\cline { 2 - 4 } \cline { 6 - 6 } & Benchmark & Pre-2009 & Polity IV & Registry \\
& estimation & sample & index & & dataset \\
\hline \hline Safe haven effect & $1.41^{* *}$ & $1.33^{* *}$ & $2.22^{*}$ & & $1.84^{* *}$ \\
\hline Country fixed effects & Yes & Yes & Yes & Yes \\
Time fixed effects & Yes & Yes & Yes & & Yes \\
\hline Observations & 1705 & 1209 & 1650 & & 1617 \\
Adj. $\mathrm{R}^{2}$ & 0.38 & 0.35 & 0.38 & & 0.30 \\
\hline
\end{tabular}


The magnitude of the effect corresponds to a house price spread between high and low foreign-origin wards arising from the shock, of 1.41 percentage points, two years following the shock.

The second column repeats the estimation for the pre-2009 sub-sample. The estimated cumulative impulse response is only marginally lower, suggesting that safe-haven effects affected the London housing market even before the recent global crisis. This finding suggests that the role of London real estate as a safe-haven asset has not only been restricted to recent years in which there has been relatively more media attention devoted to the issue.

The third column shows results when using the Polity IV index as the measure of foreign risk in place of the ICRG index. Using this measure, we find that prices are 2.22 percentage points higher in areas associated with the respective country of origin, two years year after the shock materializes.

Finally, in the fourth column, we show that foreign demand fluctuations as proxied by our foreign risk measures also drive housing transactions volumes. Similarly to the effect on prices, we find that the spread in transaction volumes between areas with high and low shares of people born in a given country is 1.84 percentage points higher, two years after the change in the foreign risk regime. We view this as encouraging evidence that our method is successful at identifying foreign demand effects that impact volume, and ultimately prices in the London residential real estate market.

\section{The Time Path of Foreign Demand Effects}

In Panel $\mathrm{A}$ of Figure 4, we estimate the evolution of the spread in response to a foreign risk shock. The results show that the predicted spread in house prices begins at 0.46 percent, and peaks at 2.49 percent. The estimated impulse response functions suggest that the effects of foreign demand on the London housing market are longlived. The relatively long lag before the effects fully materialize is consistent with the high persistence of risk, and substantial house price inertia, a likely consequence of the difficulty of arbitraging price discrepancies in the London residential real estate market.

We validate our results by using a separate transactions dataset of properties that are associated with mortgages from Nationwide building society. While these data allow us to control for a broader set of hedonic characteristics, the precision of these estimates is lower because of many fewer observations (the Nationwide sample of mortgage loans covers $6.3 \%$ of the market). 
Figure 4

The market impact of safe haven flows: time series dynamics

The figure reports the estimated cumulative response of house prices and transaction volumes in wards with high shares of foreign born people, relative to ones with low shares of foreign born people, following a shift to the high-risk regime. The empirical specifications are given by the following equations:

$$
\Delta s_{t}^{k}=\mu^{k}+\delta_{t}+\rho \Delta s_{t-1}^{k}+\sum_{l=1}^{L} \zeta_{l} z_{t-l}^{k}+u_{t}^{k}, \text { and } \Delta \nu_{t}^{k}=\omega^{k}+\tau_{t}+\gamma \Delta \nu_{t-1}^{k}+\sum_{l=1}^{L} \eta_{l} z_{t-l}^{k}+\epsilon_{t}^{k},
$$

where $\Delta s_{t}^{k}$ is the change in the price spread in period $t$ between the top and bottom $20 \%$ of wards with respect to the share of people born in country $k$ and $z_{t}^{k}$ is the risk indicator of the ICRG index of political risk. In our benchmark specification, we consider the case $L=20$ quarters. In Panel B, we report analogous impulse responses for the cross-ward spreads in transaction volumes and mortgage originations. The gray shaded areas (Registry dataset) and the dotted lines (Loans dataset) indicate 90\% confidence intervals, based on double clustered standard errors at the country and year level. We determine the statistical significance of accumulated impulse responses and impute corresponding confidence intervals based on the critical values of the F-test.

\section{Panel A}

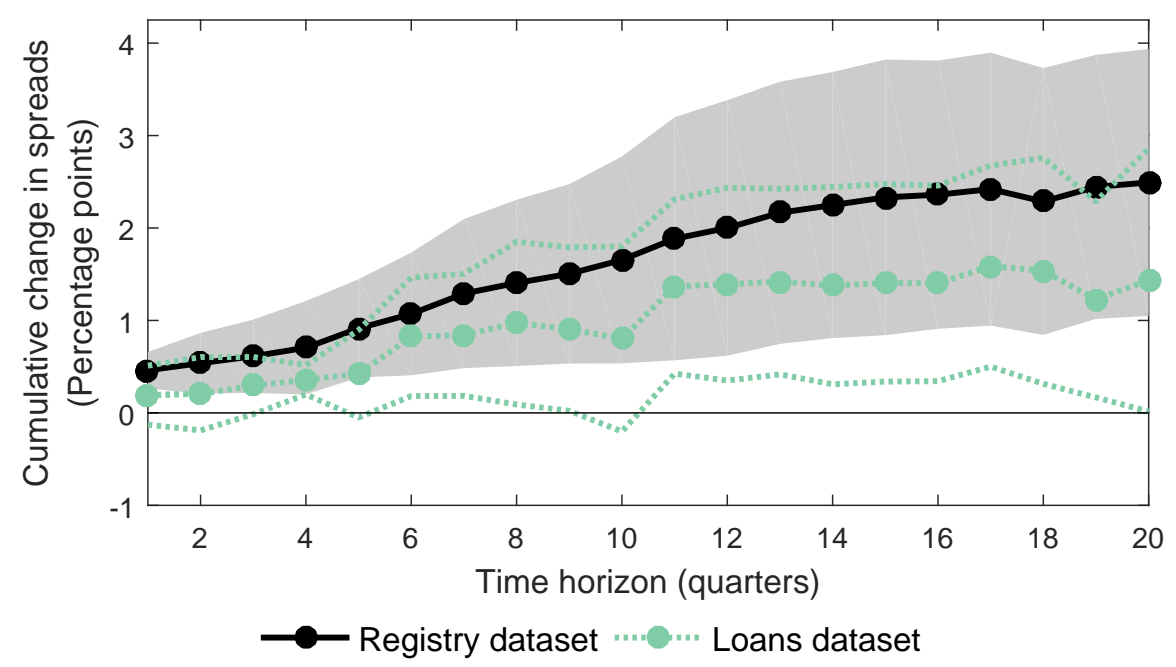

Panel B

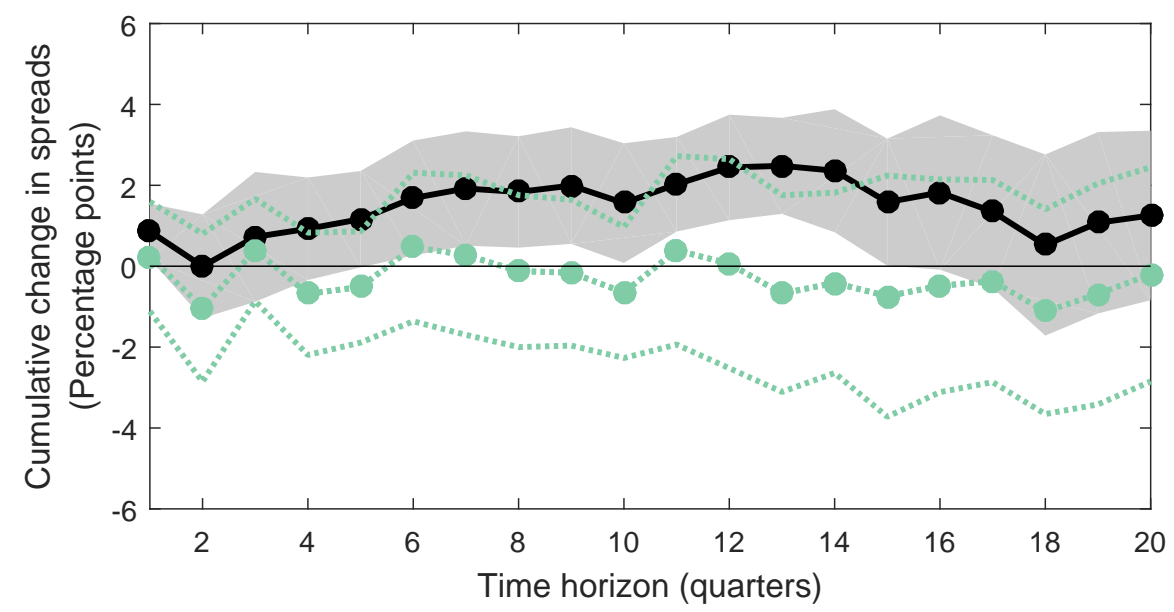

$\rightarrow$ Volume of transactions $\cdots \cdot \cdots$ Volume of mortgage loans 
In this sub-sample, we find that the predicted response of the price spread to a risk shock varies between 0.19 percent in the initial quarter and 1.58 percent four years thereafter. The magnitudes of the impulse responses are lower than the results from the Registry dataset, but they remain statistically significant, especially for longer horizons. The slightly delayed response of the house price spread calculated from loanlevel data is consistent with the presence of a spillover effect between the market for owner-occupied properties and the market for mortgage loans.

In Panel B, we show that transaction volumes in areas with relatively higher shares of foreigners also respond to changes in foreign risk. The estimation results show that the cumulative response of the spread in housing transaction volumes begins at 0.86 percent (statistically significant at a $5 \%$ confidence level), and reaches a peak at 2.48 percent. 16 quarters after the shock, the effect becomes statistically indistinguishable from zero.

Importantly, our results also suggest that the corresponding cross-ward spreads in terms of volumes of mortgage loans are unaffected by the changes in foreign risk. This is an important falsification test. If the relatively higher transaction volumes in areas preferred by foreigners were driven by domestic factors, they would likely also be visible in the total volume of mortgage loans secured with properties located in those areas. Instead, if the increases in the market activity for non-mortgaged properties are driven by foreign demand, the home-ownership demand of domestic agents and the domestic loan origination volume should remain unaffected.

\section{Contribution of Foreign Demand Effects to House Price Variation}

We find that foreign demand effects explain $7.9 \%$ of the variation in price spreads and $8.5 \%$ of the variation in transaction volumes. These numbers are calculated as the marginal unadjusted $R^{2}$ statistics (coefficient of determination) from the benchmark regression specifications (5) and (10), relative to the simpler (nested) specifications which include just country and time fixed effects. We view these numbers as lower bounds on the size of the contribution of foreign demand to the dynamics of the London residential real estate market, given our sharp focus on causal identification and all associated controls.

The next section describes a number of robustness checks to confirm and verify our results. 


\section{Robustness of the Results}

Bertrand et al. (2004) cast doubt on inferences drawn from difference-in-difference studies. They recommend a variety of techniques to improve inferences using such methods. One which they particularly recommend is based on randomization inference testing methods, which they claim work well irrespective of sample size. They suggest using the empirical distribution of estimated placebo effects to form the test distribution to evaluate the results from difference-in-difference studies. We therefore conduct a number of placebo tests to ensure that our results are robust.

A simple first placebo test is to distinguish between high- and low-risk countries. A priori, we do not expect to observe safe-haven effects for low-risk countries. In the online appendix, we show that estimated effects are indeed statistically insignificant when we estimate our benchmark specification in the sample of low-risk countries.

We then move to more formal placebo tests and simulations using randomization inference testing methods. Our first placebo simulation begins with our benchmark specification, but randomly assigns time periods during which political risk "events" counterfactually occur. In particular, we estimate:

$$
\Delta s_{t}^{k}=\mu^{k}+\delta_{t}+\rho \Delta s_{t-1}^{k}+\sum_{l=1}^{L} \widetilde{\zeta}_{l} z_{\tau-l}^{k}+u_{t}^{k},
$$

for a set of $N=2,000$ random draws (with replacement) of time periods $\tau$. In each draw we select a random $\tau \in[1, \ldots, T]$. To mimic the time series properties of $z_{t}^{k}$, we augment these draws using the standard Politis-Romano (1994) approach. That is, we also draw a random variable $\theta$ from a uniform distribution defined on $(0,1)$. If $\theta$ is smaller than a pre-set parameter $q$, we include the consecutive observation to the first draw $\tau$, i.e., $\tau+1$ in the simulated placebo time-series. If, however, $\theta$ is greater than or equal to $q$, a new observation is drawn with replacement from $\tau \in[1, \ldots, T]$. When reaching the end of the sample, the procedure starts from the beginning with $\tau=1$. At each iteration, we use the same time-series draw for all countries, to preserve any manifestation of common shocks in the data.

We report results for $q=0.75$ (our conclusions are robust to other choices of $q$ ) in Figure 5. The figure shows the histogram of estimated impulse responses at a horizon

of 2 years ( 8 quarters), arising from the distribution of placebo coefficients $\widetilde{\zeta}_{l}$. The dashed line in the figure indicates the position of the estimated impulse response equal to 1.41 percentage points, from our benchmark specification reported in Table 5. 
Figure 5

Placebo test: Time-series dimension

The figure reports the estimated distribution of the accumulated impulse response for a horizon of 2 years (8 quarters), based on estimated coefficients $\widetilde{\zeta}_{l}$ from the following quarterly panel regression specification:

$$
\Delta s_{t}^{k}=\mu^{k}+\delta_{t}+\rho \Delta s_{t-1}^{k}+\sum_{l=1}^{L} \widetilde{\zeta}_{l} z_{\tau-l}^{k}+u_{t}^{k},
$$

across a set of $\mathrm{N}=2,000$ random draws of time period blocks (with replacement) for $z_{\tau}^{k}$. In each draw, we start with a random number $\tau \in[1, \ldots, T]$, where $T$ is the maximum number of time-series observations per country. We then draw a random variable from a uniform distribution defined on $(0,1)$. If this is smaller than a parameter $q$, the consecutive observation to the first draw is also included; if it is greater than or equal to $q$, a new observation is drawn with replacement from $[1, \ldots, T]$. When reaching the end of the sample, the procedure starts from the beginning with $\tau=1$. At each iteration, we use the same time-series draw for all countries. We report results for $q=0.75$. The dashed line indicates the estimated accumulated impulse response (1.41 percentage points) for a horizon of 2 years (8 quarters), based on the benchmark coefficients $\zeta_{l}$, as reported in Table 5 .

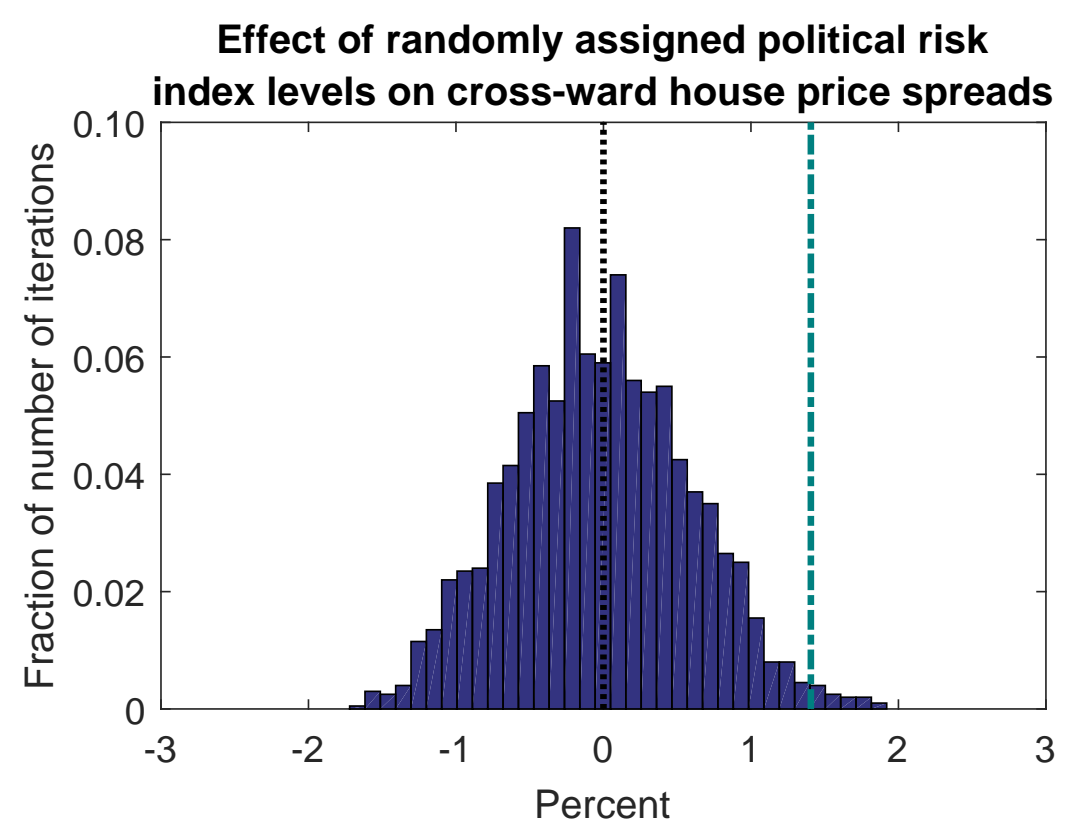


Figure 6

\section{Placebo test: Cross-sectional dimension}

The figure reports estimated distributions of accumulated impulse responses for a horizon of 2 years (8 quarters), based on estimated coefficients $\zeta_{l}$ and $\xi_{l}$ from the following quarterly panel regression specification:

$$
\Delta s_{t}^{k}=\mu^{k}+\delta_{t}+\rho \Delta s_{t-1}^{k}+\sum_{l=1}^{L} \zeta_{l} z_{t-l}^{k}+\sum_{l=1}^{L} \xi_{l} z_{t-l}^{\widetilde{k}}+u_{t}^{k}, \text { with } \widetilde{k} \in K \text { and } \widetilde{k} \neq k,
$$

across a set of $\mathrm{N}=2,000$ draws during which we pair each country $k$ with a randomly drawn country $\widetilde{k}$ (with replacement). In each draw, we consider the political risk indicator in country $\widetilde{k}$ as an additional explanatory variable. We re-estimate the panel coefficients $\zeta_{l}$ and $\xi_{l}$ for each complete cross-country set of draws. In Panel A, we report the distribution of accumulated impulse responses for a horizon of 2 years ( 8 quarters), based on estimated coefficients $\xi_{l}$ when restricting $\zeta_{l}=0$. The dashed line indicates the estimated accumulated impulse response (1.41 percentage points) based on the benchmark coefficients $\zeta_{l}$, as reported in Table 5 .

\section{Panel A}

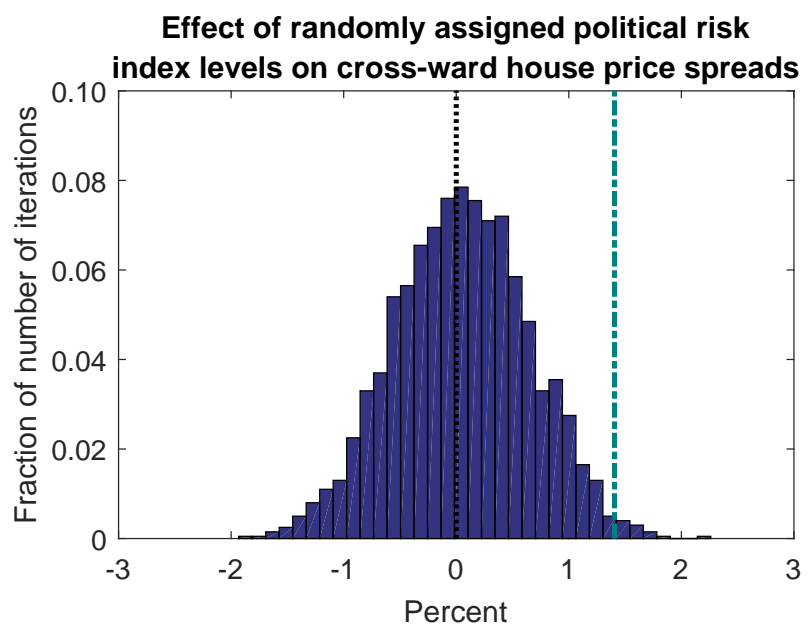

Panel B
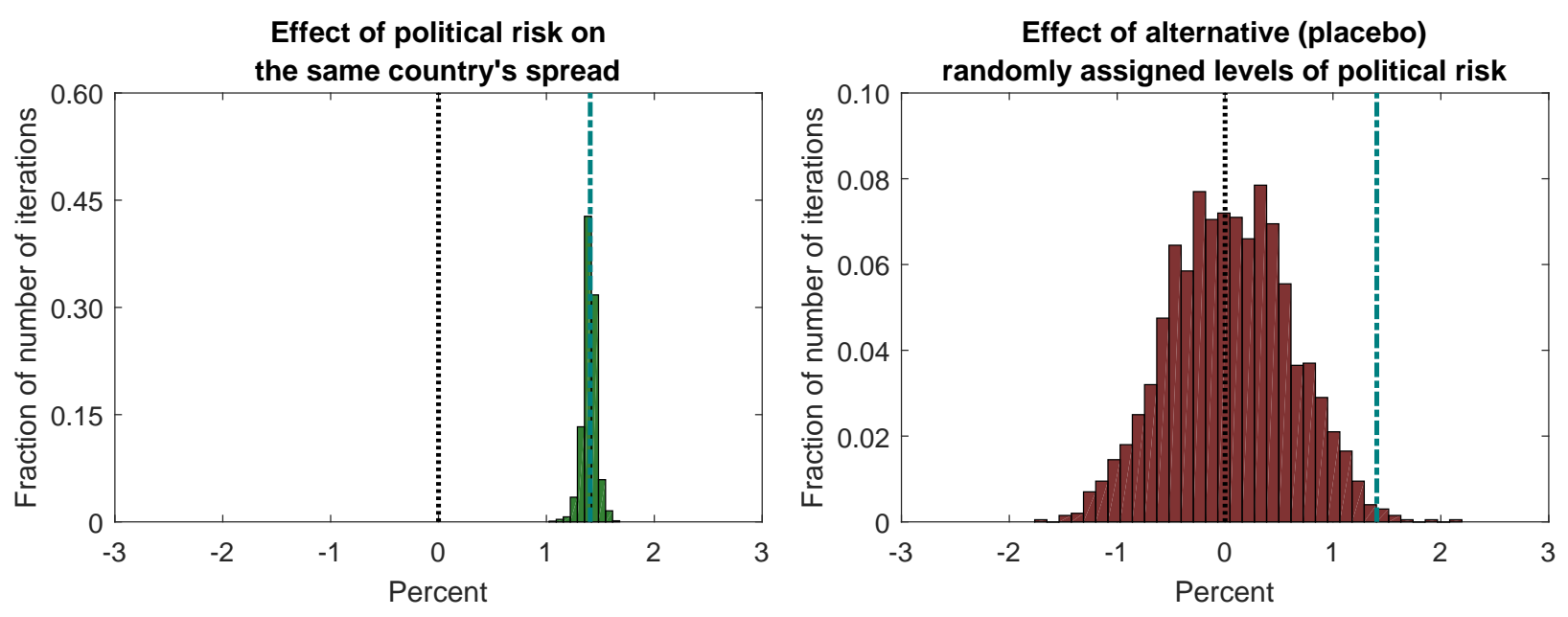
The figure shows that this estimate lies in the extreme right tail of the distribution of placebo impulse responses (the associated p-value is 0.01 ), providing reinforcement that our result is not merely a statistical artefact.

Our second placebo test checks whether we correctly map countries to regions of London using our "home bias abroad" identification approach. In this placebo experiment, we construct a synthetic variable $z_{t}^{\widetilde{k}}$ by drawing (with replacement) from the set $K \backslash k$ for each of the high-risk countries $k$. That is, we match regions of London with foreigners originating from country $k$ with movements in risk $z_{t}^{\widetilde{k}}$ from randomly selected other countries $\widetilde{k}$.

We include this placebo variable $z_{t}^{\widetilde{k}}$ in our panel regression (3) and estimate:

$$
\Delta s_{t}^{k}=\mu^{k}+\delta_{t}+\rho \Delta s_{t-1}^{k}+\sum_{l=1}^{L} \zeta_{l} z_{t-l}^{k}+\sum_{l=1}^{L} \xi_{l} z_{t-l}^{\widetilde{k}}+u_{t}^{k}, \text { with } \widetilde{k} \in K \text { and } \widetilde{k} \neq k
$$

We run 2,000 such regressions with random draws of $z_{t}^{\widetilde{k}}$. In one version of the placebo test, we restrict $\zeta_{l}=0$ to assess the power of our identification approach. In the other, we include both $z_{t-1}^{k}$ and $z_{t-1}^{\widetilde{k}}$ to check the distributions of impulse responses based on both the estimated $\zeta_{l}$ and $\xi_{l}$ coefficients.

Figure 6 reports the results of the placebo tests described in equation (12). In Panel A, we plot the distribution of the two year cumulative impulse responses based on estimated $\xi_{l}$ coefficients (when we constrain $\zeta_{l}=0$ ) across a set of $\mathrm{N}=2,000$ draws with replacement from the set of countries $K \backslash k$. We find that the benchmark point estimate of the accumulated safe haven effect at a horizon of 2 years ( 8 quarters) lies in the extreme right tail of the simulated distribution under random draws with replacement (the associated p-value is 0.007 ), providing reinforcement that our identification approach is sound.

Panel B of the figure shows what happens when we estimate both $\zeta_{l}$ and $\xi_{l}$ simultaneously. The estimated cumulative impulse response based on $\zeta_{l}$ coefficients, plotted in the left panel, varies between 1.05 and 1.67 percentage points. In contrast, the accumulated impulse response based on $\xi_{l}$ coefficients on randomly assigned risk, plotted in the right panel, varies between -1.63 and 1.88, centred close to zero, with far greater dispersion, providing additional reinforcement to our empirical approach.

We next turn to describing our inferences about the specific world regions principally associated with the foreign demand effects over our sample period, and describe how our results are connected to patterns of capital inflows and immigration into London. 


\section{Economic Interpretation and Channels}

\section{A. Analysis of World Regions}

Table 6 shows estimated cumulative impulse responses, based on the coefficients $\zeta_{l}^{\text {region }}$ estimated from equation (5) for each of the eight world regions in our sample of highrisk countries. These impulse responses are computed at different horizons, with each column corresponding to a different horizon after the initial shock. The first column shows effects one calendar quarter after the initial risk shock.

At this horizon, we find that elevated political risk in Southern Europe, Russia, South Asia, and Africa are significant sources of movements in price premia in London wards with high shares of people born in these regions. In terms of magnitudes, the largest effects occur for South-Asia and Southern Europe, which are associated with changes in the price spread of 0.84 and 0.64 percentage points respectively, one quarter following a political risk event. In contrast, at the the one year horizon, both Africa and Russia remain significant sources of foreign demand effects, and at the two year horizon, the largest effects obtain from Eastern Europe (1.46 percentage points) and Africa (1.39 percentage points).

These patterns are intriguing. Public discussion of the effects of foreign demand on London house prices has tended to focus on high-value purchases from high-net-worth individuals seeking a safe-haven for their capital in light of risk increases in their home countries. ${ }^{29}$ That said, there has also been enormous public discussion of immigration, which may also be associated with movements of foreign capital into residential real estate. At the shortest horizon, we find large effects from Southern Europe, which has the fewest frictions associated with transporting capital (and actual migration) into the UK over the sample period. However, at the longer horizons, there appear to be more significant effects of foreign demand from Russia and Africa.

We now turn to a more detailed exploration and economic interpretation of these regional effects from estimates of equation (6).

\footnotetext{
${ }^{29}$ There are also frequent statements in the popular press that foreign-origin safe-haven demand is most prevalent at the very top of the housing market. See, for example, "Foreign buyers behind half of $£ 2 \mathrm{~m}+$ home sales in London," The Guardian, 6 May 2013, and "Half of central London's £1m-plus homes go to non-UK buyers," The Telegraph, 8 October 2013.
} 


\section{Table 6}

Foreign demand and cross-ward house price spreads:

Analysis at the level of world regions

The table reports estimated coefficients from the following panel regression specification:

$$
\Delta s_{t}^{k}=\mu^{k}+\delta_{t}+\rho \Delta s_{t-1}^{k}+\sum_{l=1}^{L} \zeta_{l}^{r e g i o n} z_{t-l}^{k}+u_{t}^{k}
$$

where the coefficients $\zeta^{\text {region }}$ are allowed to vary across our set of eight world regions, but they are constrained to be the same for all countries within a region. We report accumulated impulse responses for the horizons indicated in the column header. The estimated impulse responses are multiplied by 100, for easier interpretation as percentage points. In the Benchmark case $L=20$ quarters. Inference on the statistical significance of accumulated impulse responses is based on the F-test with doubleclustered standard errors. ${ }^{*}, * *, * * *$ denote statistical significance at the $10 \%, 5 \%$, and $1 \%$ level, respectively.

\begin{tabular}{lccc}
\hline & 1 quarter & 1 year & $\begin{array}{c}\text { Benchmark } \\
2 \text { years }\end{array}$ \\
\hline \hline Southern Europe & $0.64^{* *}$ & 1.06 & 0.01 \\
Asia-Pacific & 0.23 & 1.27 & 0.85 \\
Eastern Europe & 0.37 & 0.22 & $1.46^{*}$ \\
Russia & $0.49^{* * *}$ & $0.66^{* *}$ & 0.27 \\
South-Asia & $0.84^{* *}$ & 0.88 & 0.86 \\
Africa & $0.49^{* * *}$ & $0.83^{* *}$ & $1.39^{* *}$ \\
Middle East & 0.27 & 0.31 & 0.46 \\
South-America & -0.42 & -0.07 & 0.01 \\
\hline Country fixed effects & Yes & Yes & Yes \\
Time fixed effects & Yes & Yes & Yes \\
\hline Observations & 1,705 & 1,705 & 1,705 \\
Adj. R2 & 0.37 & 0.37 & 0.44 \\
\hline
\end{tabular}




\section{B. Sources of Foreign Demand Effects}

In Table 7 , we show distributions of the $F_{j}^{k}$ variables which we employ when estimating equation (6). We first rank world regions in decreasing order of their population concentration within the city. People of South-Asian origin seem to be most clustered, which is not surprising given that in certain London wards, such as Ealing, Southall, as much as $37 \%$ of the population is of South-Asian descent (the area is popularly referred to as "Little India"). South-America is at the opposite end of the spectrum, being highly dispersed across the city.

Second, we rank countries by their absolute level of riskiness. South-Asia and Africa are generally much riskier than other parts of the world, particularly driven by countries such as Pakistan, Libya, and Egypt. In contrast, among the high-risk countries, the Asia-Pacific region is relatively less risky. That having been said, despite generally low levels of risk, high net worth investors from countries such as China are particularly sensitive to changes in the domestic environment, opting to exit the country through both capital flight and emigration (see, for example, Hess 2016).

This is consistent with the evidence in the third panel, where we report that, among our sample of high-risk countries, the Asia-Pacific region and the Middle East rank among the most important sources of capital inflows into the London commercial property market (36.2\%), alongside Southern Europe and Russia. Despite such encouraging evidence, it is clear that commercial property transactions are at best noisy measures of the flow of capital into the residential property market. To provide external validation for the use of this proxy, we therefore also inspect information from London real estate agency reports. We find that by and large, the ranking of the foreign sources of commercial property flows corresponds reasonably well to the information about residential property flows from these agency reports, with one exception, the Middle East. For this region, which accounts for a high share of cross-border commercial property transactions, evidence reported by real estate agencies during the past few years suggests that it only accounts for $2.7 \%$ of residential purchases, even in the Prime Central London region. This suggests that for the city as a whole, the share of residential property flows accounted for by this region is likely to be even lower (we report this evidence in the online appendix). To correct for noise in estimation from this source, we therefore adjust the relative contribution of the Middle Eastern region to inbound capital flows to $2.7 \%$.

Finally, we turn to immigration flows into London. Of the high-risk countries in our sample, Eastern Europe accounts for 31.4\% of population inflows over the 2002 to 2013 period, well above South-Asia and Southern Europe. 


\section{Table 7}

\section{Determinants of safe haven effects across world regions}

The table reports measures of population concentration within the city (calculated as relative crossward standard deviations), absolute levels of riskiness (calculated as average levels of the ICRG index), inbound capital flows (calculated as relative contributions of different regions to total transaction volumes of commercial property in London), and inbound immigration flows (calculated as relative contributions of different regions to total registrations with National Insurance in London). The data sources are the Office of National Statistics, the PRS Group, and the commercial property transactions database provided by Real Capital Analytics.

Population concentration within the city

\begin{tabular}{ll}
\hline South-Asia & 1.80 \\
Middle East & 1.50 \\
Africa & 1.16 \\
Southern Europe & 1.13 \\
Asia-Pacific & 1.05 \\
Eastern Europe & 0.99 \\
Russia & 0.95 \\
South-America & 0.94 \\
\hline
\end{tabular}

Inbound commercial property capital flows

\begin{tabular}{lr}
\hline Middle East & $36.2 \%$ \\
Asia-Pacific & $32.5 \%$ \\
Southern Europe & $21.1 \%$ \\
Russia & $5.1 \%$ \\
South-Asia & $4.8 \%$ \\
South-America & $0.2 \%$ \\
Eastern Europe & $0.1 \%$ \\
Africa & $0.0 \%$ \\
\hline
\end{tabular}

\begin{tabular}{lc}
\hline Absolute level of riskiness & \\
\hline Africa & 45.70 \\
South-Asia & 45.29 \\
Russia & 38.59 \\
Middle East & 36.96 \\
South-America & 29.01 \\
Eastern Europe & 24.57 \\
Southern Europe & 21.77 \\
Asia-Pacific & 20.29 \\
\hline & \\
\hline Inbound immigration flows & \\
\hline Eastern Europe & $31.4 \%$ \\
South-Asia & $21.6 \%$ \\
Southern Europe & $19.0 \%$ \\
Asia-Pacific & $11.4 \%$ \\
Africa & $9.7 \%$ \\
Middle East & $3.8 \%$ \\
South-America & $2.4 \%$ \\
Russia & $0.6 \%$ \\
\hline
\end{tabular}


This is driven in particular by the EU accession process of countries such as Poland and Romania, but is not a mere artefact of the opening of borders. Countries in the region have also experienced political risk events (such as the 2006 turmoil within the coalition forming the Kaczynski government in Poland, and the rapid succession of regime changes in Romania in the years 2000 and 2010) that have likely served as triggers for the migration of the population. Similarly, after the sovereign debt crisis of 2010-2011, people from Southern European countries have been relatively more attracted by the London labour market. Interestingly, despite featuring very prominently in the public discourse, there seems to be only a very small number of Russian individuals that have actually migrated towards London in recent years. Below, we discuss the issue in more detail, and show that the increase in political risk in Russia is indeed associated with higher population inflows into London, but the composition of these population inflows is decidedly skewed towards high net-worth individuals.

We then use these variables to analyze the heterogeneity of estimated foreign demand effects for different parts of the world. In Table 8 we report cumulative impulse responses of cross-ward house price spreads to foreign risk shocks, based on the estimated coefficients from equation (6). The first row of the table shows that, once we condition the foreign demand effects on our set of four independent variables, the unconditional impulse response becomes statistically indistinguishable from zero, particularly at longer horizons. The second row shows that the cross-country heterogeneity of estimated foreign demand effects is unrelated to the concentration of the foreign population within the city. This is an important empirical validation of our identification approach.

The third row of the table shows that across all horizons the estimated foreigndemand effects are larger for countries which have a generally higher level of political risk. In Table 6 , we found significant foreign demand effects particularly from Africa and Russia - which are two of the regions of the world with the highest absolute level of the composite ICRG index from Table 7.

Not surprisingly, the interaction term capturing the role of risk has a strongly statistically significant effect - suggesting that foreign shocks have a 0.76 percentage points higher impact on the London real estate market, at a horizon of 2 years, if they occur in countries that are $50 \%$ more risky than the average country in our sample (e.g. the difference between the Middle East and Africa).

The fifth row of the table allows us to link the observed foreign demand effects with the migration channel and the associated transfer of resources towards the London market. 


\section{Table 8}

Foreign demand and cross-ward house price spreads: Explaining cross-regional heterogeneity

The table reports estimated coefficients from the following panel regression specification:

$$
\Delta s_{t}^{k}=\mu^{k}+\delta_{t}+\rho \Delta s_{t-1}^{k}+\sum_{l=1}^{L}\left(\zeta_{l}+\sum_{j=1}^{4} \xi_{j, l} F_{j}^{k}\right) z_{t-l}^{k}+u_{t}^{k},
$$

where the $F^{k}$ variables are measures of population concentration within the city (calculated as relative cross-ward standard deviations), absolute levels of riskiness (calculated as average levels of the ICRG index), inbound capital flows (calculated as relative contributions of different regions to total transaction volumes of commercial property in London) and inbound immigration flows (calculated as relative contributions of different regions to total registrations with National Insurance in London). For the two latter variables, we use region-level averages for each country in a given region. We report accumulated impulse responses for the horizons indicated in the column header. The estimated impulse responses are multiplied by 100 , for easier interpretation as percentage points. Inference on the statistical significance of accumulated impulse responses is based on the F-test with double-clustered standard errors. ${ }^{*},{ }^{* *},{ }^{* *}$ denote statistical significance at the $10 \%, 5 \%$, and $1 \%$ level, respectively.

\begin{tabular}{lccc}
\hline & 1 quarter & 1 year & $\begin{array}{c}\text { Benchmark } \\
2 \text { years }\end{array}$ \\
\hline \hline Unconditional effect & & & -1.85 \\
Interaction terms: & & & \\
- Concentration within city & 0.12 & 0.00 & -0.21 \\
- Absolute level of riskiness & $0.58^{* * *}$ & $1.31^{*}$ & $1.52^{*}$ \\
- Inbound capital flows & 1.40 & $5.18^{*}$ & 2.29 \\
- Inbound immigration flows & $2.54^{* *}$ & 2.33 & 5.47 \\
\hline Country fixed effects & Yes & Yes & Yes \\
Time fixed effects & Yes & Yes & Yes \\
\hline Observations & 1,705 & 1,705 & 1,705 \\
Adj. R2 & 0.37 & 0.37 & 0.42 \\
\hline
\end{tabular}


Our results imply that a $10 \%$ increase in immigration is associated with a 0.25 percent increase in the short-term response of cross-ward price spreads to a foreign shock (for a horizon of 1 quarter). This concerns particularly Southern Europe and SouthAsia. We believe a relatively quick reaction of the London market to developments in Southern Europe is plausible, given the absence of capital flow and immigration restrictions within the European Union and the strong financial ties between the UK and continental Europe. Similarly, the large concentration of people of South-Asian origin located in London is likely associated with a rapid transfer of resources towards the domestic market, in response to significantly disruptive events abroad, potentially reflecting a precautionary and wealth preservation motive.

Finally, when we consider an estimation horizon of 1 year, the impact of foreign demand tends to be more aligned with the cross-country pattern of capital flows, with the Asia-Pacific region and Russia becoming more dominant. This leads to a large and statistically significant coefficient for the interaction term capturing inbound capital flows, suggesting that about 1 year after the risk shock materializes, the types of foreign capital flowing into the residential market are more related to a pure wealth transfer and safe haven motive, and not dissimilar from the ones affecting the market for commercial property.

We admittedly have less power in these specifications than in our baseline specification. Nevertheless, a reasonable interpretation of the timeline of foreign demand effects implied by our results is that there is (a) a short-term response of London house prices to flows from neighbouring countries as well as to increased purchases by the local population (funded perhaps through reduced remittance flows back to their countries of origin at such times), followed by (b) transfers of capital from countries experiencing significant political turmoil to a safe haven market, with pricing effects visible 1 to 2 years after the initial shock.

In the next section, we provide additional validation for these economic mechanisms, exploiting a number of alternative datasets.

\section{Safe-Haven Effects and Immigration}

To extend our exploration of the immigration channel, we estimate:

$$
\Delta f_{w, 2011}^{k}=\alpha+\rho^{k} f_{w, 2001}^{k}+\beta^{k} \Delta f_{w, 2011}^{U K}+e_{w, 2011}^{k}
$$

In this specification, we condition the change between 2011 and $2001 \Delta f_{w, 2011}^{k}=$ $f_{w, 2011}^{k}-f_{w, 2001}^{k}$ in the share of people in ward $w$ originating from country $k$ on the 
starting level of this share in 2001, $f_{w, 2001}^{k}$. The sign and significance of the coefficient $\rho^{k}$ indicates the degree to which immigrants from country $k$ move into wards with a pre-existing high share of people originating from their home country. $\Delta f_{w, 2011}^{U K}$ is the change in the share of UK-origin residents in London wards, and eliminates variation in immigration shares that are mechanically generated by aggregate variation in the relative populations of foreign-vs-domestic origin residents. This variable can only be constructed for a small part of our sample, because of the change in country taxonomies between the 2001 and 2011 waves of the UK census. Foreign-born people shares, separately identified in both the 2001 and 2011 Census waves, are only available for the smaller subset of countries.

Equation (13) also provides further evidence on our identification strategy, if $\rho^{k}$ is estimated to be significantly positive - although it is worth noting again that our identification strategy is not conditional on immigration flows actually materializing. This possibility of the immigration channel also relates to the relative pace of financial market transactions and those in real goods and services markets.

When political or economic risks actually materialize, relatively fast moving capital flows towards London properties may be followed by relatively slow-moving subsequent increases in immigration. (The online appendix investigates, to the extent permitted by the data, whether price increases in wards with higher shares of foreign-born people can forecast increases in future immigration into those wards.)

Table 9 shows estimates of equation (13) for the countries for which we are able to track changes in ward-level shares of foreign-born people between the two (2001 and 2011) waves of the census. The table shows that for a large set of countries there is a strong, statistically significant correlation between these changes and the initial levels of ward-level foreign-born shares in 2001. This lends credibility to our identification approach despite the reduced set of countries for which we are able to estimate this relationship. It is the case, however, for a smaller set of countries which includes Jamaica, Kenya, Bangladesh, and Zimbabwe, that we see the opposite pattern, namely that immigration to wards with high shares of residents originating from these countries is significantly lower than in other areas of London.

We complement this simple analysis by analyzing two additional sets of immigration statistics, one of which is potentially informative about the immigration channel and the other about safe-haven effects.

First, we obtain the numbers of registrations for National Insurance from the UK Department for Work and Pensions. 


\section{Table 9}

\section{The evolution of foreign-born people shares through time}

The table reports estimated coefficients $\rho^{k}$ from the regression:

$$
\Delta f_{w, 2011}^{k}=\alpha+\rho^{k} f_{w, 2001}^{k}+\beta^{k} \Delta f_{w, 2011}^{U K}+e_{w, 2011}^{k},
$$

where we condition the change between 2011 and 2001 in the share of people in ward $w$ originating from country $k$ on the starting level of this share in 2001. The estimation sample consists of the 624 London wards. The estimated standard errors, reported in parentheses, are White heteroskedasticity-robust. $*, * *, * * *$ denote statistical significance at the $10 \%, 5 \%$, and $1 \%$ level, respectively.

\begin{tabular}{ll}
\hline India & $0.63^{* * *}$ \\
& $(0.08)$ \\
Pakistan & $0.50^{* * *}$ \\
& $(0.08)$ \\
Sri Lanka & $0.46^{* * *}$ \\
& $(0.11)$ \\
Poland & $0.42^{* * *}$ \\
& $(0.05)$ \\
Somalia & $0.40^{* * *}$ \\
& $(0.08)$ \\
Italy & $0.37^{* * *}$ \\
& $(0.04)$ \\
China & $0.36^{* * *}$ \\
& $(0.07)$ \\
Spain & $0.30^{* * *}$ \\
& $(0.07)$ \\
Romania & $0.16^{* * *}$ \\
& $(0.04)$ \\
South Africa & 0.07 \\
& $(0.10)$ \\
Nigeria & 0.02 \\
& $(0.06)$ \\
Jamaica & $-0.44^{* * *}$ \\
& $(0.07)$ \\
Kenya & $-0.46^{* * *}$ \\
& $(0.11)$ \\
Bangladesh & $-0.48^{* * *}$ \\
& $(0.15)$ \\
Zimbabwe & $-0.53^{* * *}$ \\
& $(0.05)$ \\
\hline &
\end{tabular}


Second, we obtain the numbers of visas granted to foreign citizens during the period between 2008 and 2013 from the UK Border Agency, with a particular focus on Tier 1 (Investor) visas. Such visas are granted to foreign investors investing more than £2 million in UK government bonds, share capital, or loan capital in active registered companies, and as such, would be expected to have more to do with safe-haven effects than immigration. ${ }^{30}$ The issuance of such visas mean that foreign capital flows and flows of people to the UK can explicitly be linked to one another. The question is whether they are also linked to risk in source countries.

The top panel of Figure 7 shows that for countries for which a visa is not generally necessary to enter and work in the UK, high levels of political risk in a given country are associated with a higher propensity of the residents of that country to enter the UK labour market during the period between 2008 and 2013. This appears to hold especially for the Southern European region, which we also find to be an important source of foreign demand for London real estate, at least for shorter horizons.

For some countries, such as China, Russia, Turkey, Libya, and South Africa, the rate of immigration does not seem to rise in response to substantial increases in political risk. However, we find that for all of these countries, the number of investment visas increases dramatically over the period, e.g. by a factor of 10 for China, 8 for Libya, 4 for Turkey and Russia, and 3 for South Africa. The cases of Syria and Libya are particularly interesting. Both are subject to massively disruptive internal conflicts, but the populations of these countries seem to have responded very differently as far as movements to the UK are concerned. In the case of Syria, immigration into the UK has picked up rapidly and is reflected in a significant presence in the local labour market, while in the case of Libya, immigration has been low, but a much larger number of high-worth individuals have moved substantial amounts of capital into the UK market.

The bottom panel of Figure 7 shows that there is even more broadly a strong positive correlation between changes in risk in countries requiring a visa to enter the UK, and the number of investor visas granted by the UK to citizens of those countries. The online appendix shows that this positive association between country political risk and visas granted to residents of the country is restricted to the Tier 1 (Investor) type.

That is, in the (relatively poorer) countries for which a visa is necessary in order to enter the UK, political risk appears to be associated with movements to the UK predominantly for the wealthiest individuals.

\footnotetext{
${ }^{30}$ In order to obtain an investor visa, foreign nationals have to prove their ability and express the intention to invest more than $£ 2$ million in the country. The visas are initially granted for a period of three years. Note that direct investments in companies engaged in property investment, property management or property development are not considered legitimate grounds for obtaining a Tier 1 visa.
} 


\section{Figure 7}

Foreign political risk, migration and investment flows

In the top panel, we report the total number of registrations for National Insurance in London, for selected population groups, for the year 2013 relative to 2008. In the bottom panel, we report the number of Tier 1 (Investor) visas granted in 2013, relative to 2008. Tier 1 visas are granted to citizens from outside the European Economic Area and Switzerland that invest more than $£ 2$ million in the UK. The lines indicate univariate cross-country fitted values. On the horizontal axis, we report the change in political risk (measured by the ICRG index) during the same period. In this representation, we exclude low-risk countries, those which are not in our main estimation sample and countries for which the number of visas or the number of people registered with National Insurance in London are equal to zero in both periods.
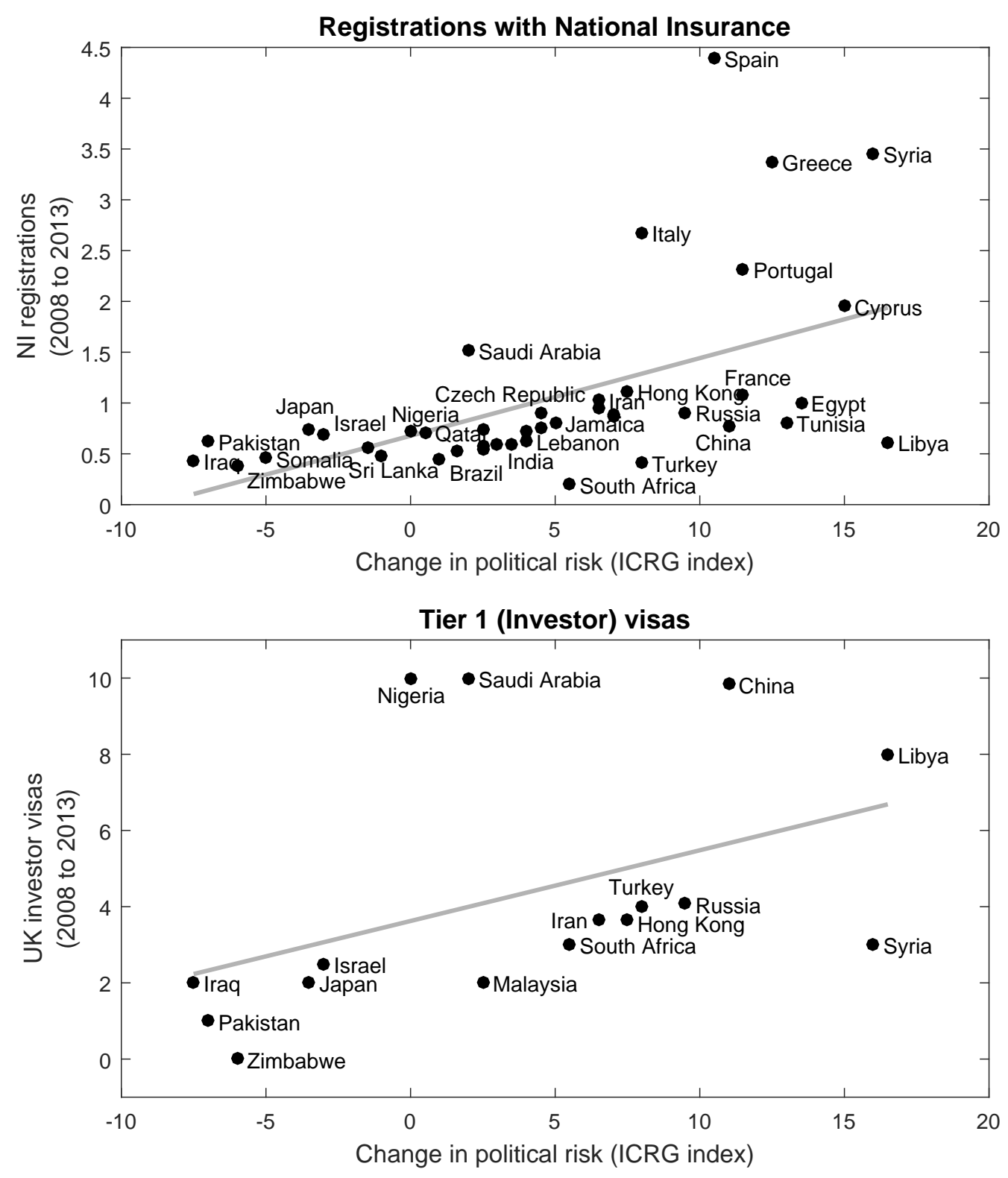
Overall, the evidence from visas points to two sources of effects, one of which may be connected to the Lucas puzzle. Political economy explanations of the Lucas puzzle concentrate on the motivations of those most likely to suffer expropriation or taxation consequences in poor countries, i.e., the wealthiest residents of those countries, who have the ability to achieve "escape velocity" from their home countries. We find evidence in the investor visas that suggests that this is an important part of the story. The second source arises from movements in political risk in countries which face relatively low impediments to moving labour to London, such as the Southern European countries. Taken together, we find suggestive evidence that both immigration and safe-haven effects may be responsible for the demand effects that we detect on London residential real estate prices.

\section{Conclusions}

In this paper, we propose a novel method to identify the impact of demand on asset prices, which relies on the fact that investors may have different "preferred habitats" for their capital within a broad asset class. Using this method and large micro-datasets of housing transactions in London, we find economically large, statistically significant, and robust effects of foreign risk on house prices in locations in which the shares of foreign-origin London residents are high.

Our empirical results provide a careful analysis of whether foreign capital flows have affected real estate prices and price volatility, especially in global cities such as London and New York. This is a phenomenon that has been widely commented upon in the press, and been the subject of numerous policy debates, but has not been supported by rigorous empirical work thus far. We view our results as a more general contribution to the analysis of macro-variation in prices, by using an identification strategy that is grounded in agents' microeconomic motivations. 


\section{References}

Aizenman, J. and Y. Jinjarak, 2009, "Current Account Patterns and National Real Estate Markets", Journal of Urban Economics, 66, 75-89.

Alfaro, L., S. Kalemli-Ozcan and V. Volosovych, 2008, "Why Doesn't Capital Flow from Rich to Poor Countries? An Empirical Investigation", Review of Economics and Statistics, 90(2), 347-368.

Badarinza, C. and T. Ramadorai, 2016, Online appendix to "Home Away From Home? Foreign Demand and London House Prices", http://household-finance.net/node/304.

Baker, S., N. Bloom and S. J. Davis, 2013, "Measuring Economic Policy Uncertainty", Chicago Booth Research Paper No. 13-02.

Baur, D. G. and T. K. McDermott, 2010, "Is Gold a Safe Haven? International Evidence", Journal of Banking and Finance, 34(8), 1886-1898.

Beber A., M. W. Brandt and K. Kavajecz, 2009, "Flight-to-Quality or Flight-toLiquidity? Evidence from the Euro-Area Bond Market", Review of Financial Studies, 22, 925-957.

Bertrand, M., E. Duflo, and S. Mullainathan, 2004, "How Much Should We Trust Differences-in-Differences Estimates?" Quarterly Journal of Economics, 119, 249275.

Bollerslev, T., Patton, A., and W. Wang, 2013, "Daily House Price Indexes: Construction, Modeling, and Longer-Run Predictions", Unpublished working paper.

Braid, R. M., 1981, "The Short-Run Comparative Statics of a Rental Housing Market", Journal of Urban Economics, 10(3), 286-310.

Broner, F., Gelos, R. G., and C. Reinhart, 2006, "When in Peril, Retrench: Testing the Portfolio Channel of Contagion", Journal of International Economics, 69, 203-230.

Broner, F., Didier, T., Erce, A., and S. L. Schmukler, 2013, "Gross Capital Flows: Dynamics and Crises", Journal of Monetary Economics, 60, 113-133.

Brunnermeier, Markus K, and Christian Julliard, 2008, "Money Illusion and Housing Frenzies", Review of Financial Studies, 21, 135-180. 
Caballero, R. J. and A. Krishnamurthy, 2009, "Global Imbalances and Financial Fragility", American Economic Review, 99(2), 584-88.

Caballero, R. J., E. Farhi, and P. O. Gourinchas, 2008, "An Equilibrium Model of Global Imbalances and Low Interest Rates", American Economic Review, 98(1), 358-393.

Cameron, A. C., Gelbach J. B., and D. L. Miller, 2011, "Robust Inference With Multiway Clustering", Journal of Business and Economic Statistics, 29(2), 238249.

Campbell, J. Y., S. Giglio, and P. Pathak, 2011, "Forced Sales and House Prices", American Economic Review, 101(5), 2108-2139.

Campbell, J. Y., K. Serfaty-de Medeiros and L. M. Viceira, 2010, "Global Currency Hedging", Journal of Finance, 65(1), 87-121.

Card, D., 2001, "Immigrant Inflows, Native Outflows, and the Local Market Impacts of Higher Immigration", Journal of Labor Economics, 19(1), 22-64.

Card, D., and J. DiNardo, 2000, "Do Immigrant Inflows Lead to Native Outflows?" American Economic Review, 90(2), 360-367.

Case, K. E., and R. J. Shiller, 1989, "The Efficiency of the Market for Single-Family Homes", American Economic Review, 79(1), 125-137.

Choi, H. S., H. Hong, J. Kubik and J. P. Thompson, 2015, "When Real Estate is the Only Game in Town", Unpublished working paper.

Claessens, S. and K. Forbes, 2001, International Financial Contagion, Kluwer Academic Publishers, Boston.

Cohen, L., 2009, "Loyalty-Based Portfolio Choice", The Review of Financial Studies, $22(3), 1213-1245$.

Coval, J. D. and T. J. Moskowitz, 2001, "The Geography of Investment: Informed Trading and Asset Prices", Journal of Political Economy, 109(4), 811-841.

Culbertson, J., 1957, "The Term Structure of Interest Rates", Quarterly Journal of Economics, 71, 485-517.

Dorn, D., and G. Huberman, 2010, "Preferred Risk Habitat of Individual Investors", Journal of Financial Economics, 97(1), 155-173. 
Driscoll, J. C., and A. C. Kraay, 1998, "Consistent Covariance Matrix Estimation with Spatially Dependent Panel Data", Review of Economics and Statistics, 80, 549-560.

Erb, C. B., C. R. Harvey and T. E. Viskanta, 1996a, "The Influence of Political, Economic, and Financial Risk on Expected Fixed-Income Returns", Journal of Fixed Income, 6(1), 7-30.

Erb, C. B., C. R. Harvey and T. E. Viskanta, 1996b, "Political Risk, Economic Risk, and Financial Risk", Financial Analysts Journal, 52(6), 29-46.

Favilukis, J., D. Kohn, S.C. Ludvigson. and S. Van Nieuweburgh, 2013, "International Capital Flows and House Prices: Theory and Evidence", Housing and the Financial Crisis, NBER, Cambridge, MA., Chapter 8.

Forbes, K. J., and F. E. Warnock, 2012, "Capital Flow Waves: Surges, Stops, Flight, and Retrenchment", Journal of International Economics, 88(2), 235-251.

Genesove, D. and C. Mayer, 2001, "Loss Aversion And Seller Behavior: Evidence From the Housing Market", Quarterly Journal of Economics, 116(4), 1233-1260.

Gertler, M., and K. Rogoff, 1990, "North-South Lending and Endogenous Domestic Capital Market Inefficiencies", Journal of Monetary Economics, 26, 245-266.

Glaeser, E. L., R. La Porta, F. Lopez-de-Silanes and A. Shleifer, 2004, "Do Institutions Cause Growth?", Journal of Economic Growth, 9(3), 271-303.

Goetzmann, W. N., Peng, L., and J. Yen, 2012, "The Subprime Crisis and House Price Appreciation", Journal of Real Estate Finance and Economics, 44, 36-66.

Greenwood, R. and D. Vayanos, 2010, "Price Pressure in the Government Bond Market", American Economic Review, 100(2), 585-90.

Guerrieri, V., D. Hartley and E. Hurst, 2013, "Endogenous Gentrification and Housing Price Dynamics", Journal of Public Economics, 100(C), 45-60.

Gyourko, J., C. Mayer and T. Sinai, 2013, "Superstar Cities", American Economic Journal: Economic Policy, 5(4), 167-99.

Hess, Steve, 2016, "The Flight of the Affluent in Contemporary China", Asian Survey, $56(4), 629-650$. 
Jinjarak, Y. and S. M. Sheffrin, 2011, "Causality, Real Estate Prices, and the Current Account", Journal of Macroeconomics, 33, 233-246.

Jotikasthira, C., Lundblad, C., and T. Ramadorai, 2012, "Asset Fire Sales and Purchases and the International Transmission of Funding Shocks", Journal of Finance, 67, 2015-2050.

Kaminsky, G., Lyons, R. K., and S. Schmukler, 2004, "Managers, investors, and crises: Investment strategies of mutual funds", Journal of International Economics, 64, 113-134.

Karolyi, G. A., 2003, "Does International Financial Contagion Really Exist?", International Finance, 6(2), 179-199.

Landvoigt, T., M. Piazzesi and M. Schneider, 2015, "The Housing Markets(s) of San Diego", American Economic Review, 4(105), 1371-1407.

Lewis, K. K., 1999, "Trying to Explain Home Bias in Equities and Consumption", Journal of Economic Literature, 37(2), 571-608.

Longstaff, F. A., 2004, "The Flight-to-Liquidity Premium in U.S. Treasury Bond Prices", Journal of Business, 77(3), 511-526.

Longstaff, F. A., Pan, J., Pedersen, L. H., and K. J. Singleton, 2011, "How Sovereign Is Sovereign Credit Risk?", American Economic Journal: Macroeconomics, 3(2), 75-103.

Mian, A. and A. Sufi, 2009, "The Consequences of Mortgage Credit Expansion: Evidence from the U.S. Mortgage Default Crisis", Quarterly Journal of Economics, 124(4), 1449-1496.

Meese, R. A. and N. E. Wallace, 1997, "The Construction of Residential Housing Price Indices: A Comparison of Repeat-Sales, Hedonic-Regression, and Hybrid Approaches", Journal of Real Estate Finance and Economics, 14, 51-73.

Modigliani, F. and R. Sutch, 1966, "Innovations in Interest-Rate Policy", American Economic Review, 56, 178-197.

Ngai, R., and S. Tenreyro, 2014, "Hot and Cold Seasons in the Housing Market", American Economic Review, 104, 3991-4026. 
Ortalo-Magné, F. and S. Rady, 2006, "Housing Market Dynamics: On the Contribution of Income Shocks and Credit Constraints", Review of Economic Studies, $73(2), 459-485$.

Ottaviano, G., and G. Perri, 2006, "The Economic Value of Cultural Diversity: Evidence from US Cities", Journal of Economic Geography, 6(1), 9-44.

Politis, D. N., and J. P. Romano, 1994, "The Stationary Bootstrap, " Journal of the American Statistical Association 89, 1303-1313.

Ranaldo, A. and P. Söderlind, 2010, "Safe Haven Currencies", Review of Finance, 10, 385-407.

Rodrik, D. and R. Wacziarg, 2005, "Do Democratic Transitions Produce Bad Economic Outcomes?", American Economic Review, 95(2), 50-55.

Rosen, S., 1974, "Hedonic Prices and Implicit Markets: Product Differentiation in Pure Competition", Journal of Political Economy, 82(1), 34-55.

Sa, F., 2015, "Immigration and House Prices in the UK", Economic Journal, 125(587), 1393-1424.

Sa, F., 2016, "The Effect of Foreign Investors on Local Housing Markets: Evidence from the UK", Unpublished working paper.

Saiz, A. and S. Wachter, 2011, "Immigration and the Neighborhood", American Economic Journal: Economic Policy, 3(2), 169-88.

Stark, O. and R. Lucas, 1988, "Migration, Remittances, and the Family", Economic Development and Cultural Change, 465-481.

Stein, J., 1995, "Prices and Trading Volume in the Housing Market: A Model with Down-Payment Effects", Quarterly Journal of Economics, 110, 379-406.

Stroebel, J., and Vavra, J., 2015, "House Prices, Local Demand, and Retail Prices," Unpublished working paper.

Tabellini, G., 2010, "Culture and Institutions: Economic Development in the Regions of Europe", Journal of the European Economic Association, 8(4), 677-716.

Thompson, S., 2011, "Simple formulas for standard errors that cluster by both firm and time", Journal of Financial Economics, 99(1), 1-10. 
Transparency International, 2015, "Corruption at Your Doorstep", London.

Vayanos, D., and J-L Vila, 2009, "A Preferred-Habitat Model of the Term Structure of Interest Rates", Unpublished working paper.

World Bank, 2015, "Migrants' Remittances from the United Kingdom - A Greenback 2.0 Report". 
Online Appendix for

\section{Home Away From Home? Foreign Demand and London House Prices}




\section{List of Figures}

A.1 Foreign-born people shares in London . . . . . . . . . . . . . 2

A.2 Average levels of political risk . . . . . . . . . . . . . 3

A.3 Cross-ward distribution of demographic, social and economic variables 4

A.4 Cross-ward distribution of the foreign-born people shares . . . . . . 5

A.5 Time series of capital flows into London's commercial real estate market 7

A.6 Foreign political risk and migration into the UK . . . . . . . . 8

A.7 Robustness check: clustering at the level of world regions . . . . . . 9

A.8 Nationalities of buyers in the Prime Central London area . . . . . . 11

A.9 Relationship between house prices and immigration shares . . . . . . 18

\section{List of Tables}

A.1 Summary statistics across wards . . . . . . . . . . . . . 10

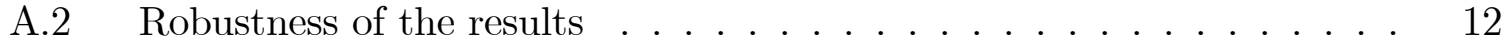

A.3 The role of individual components of the ICRG risk index . . . . . . 13

A.4 Cross-ward correlation between country of birth and ethnic group . . . 14

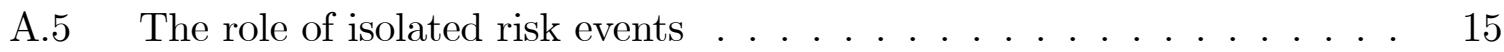




\section{FiguRE A.1}

Foreign-born people shares in London

The figure reports the overall shares of foreign-born people in London. We use these shares in order to construct weighted averages of variables.
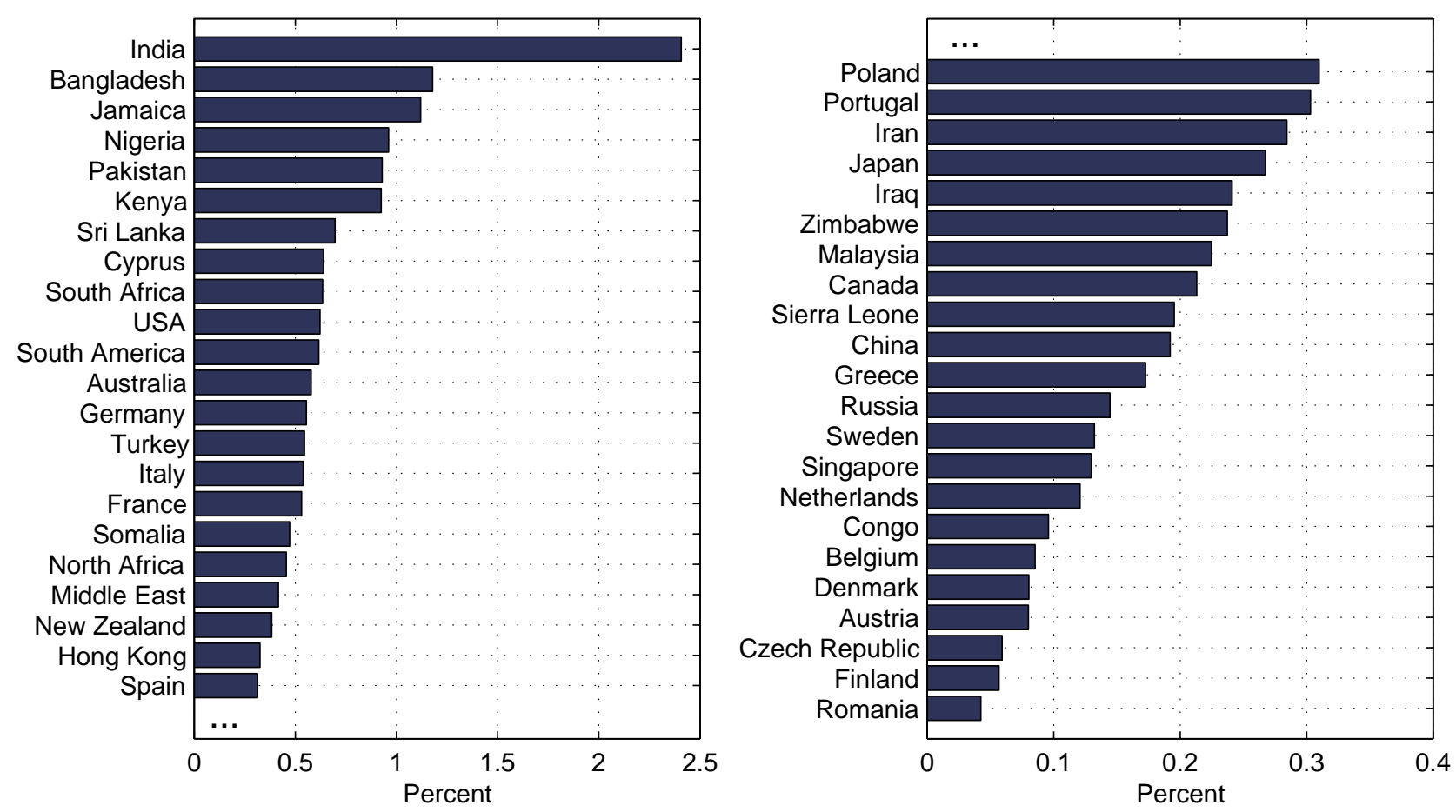


\section{FiguRE A.2}

\section{Average levels of political risk}

The figure reports average levels of political risk, as captured by the ICRG indexes. In our estimation, we distinguish between countries with high political risk (higher than a threshold of 20) and low political risk (lower than 20). We adjust the raw index series reported by the PRS Group by subtracting them from a total value of 100 . This insures that we can interpret higher index values as increases in risk.
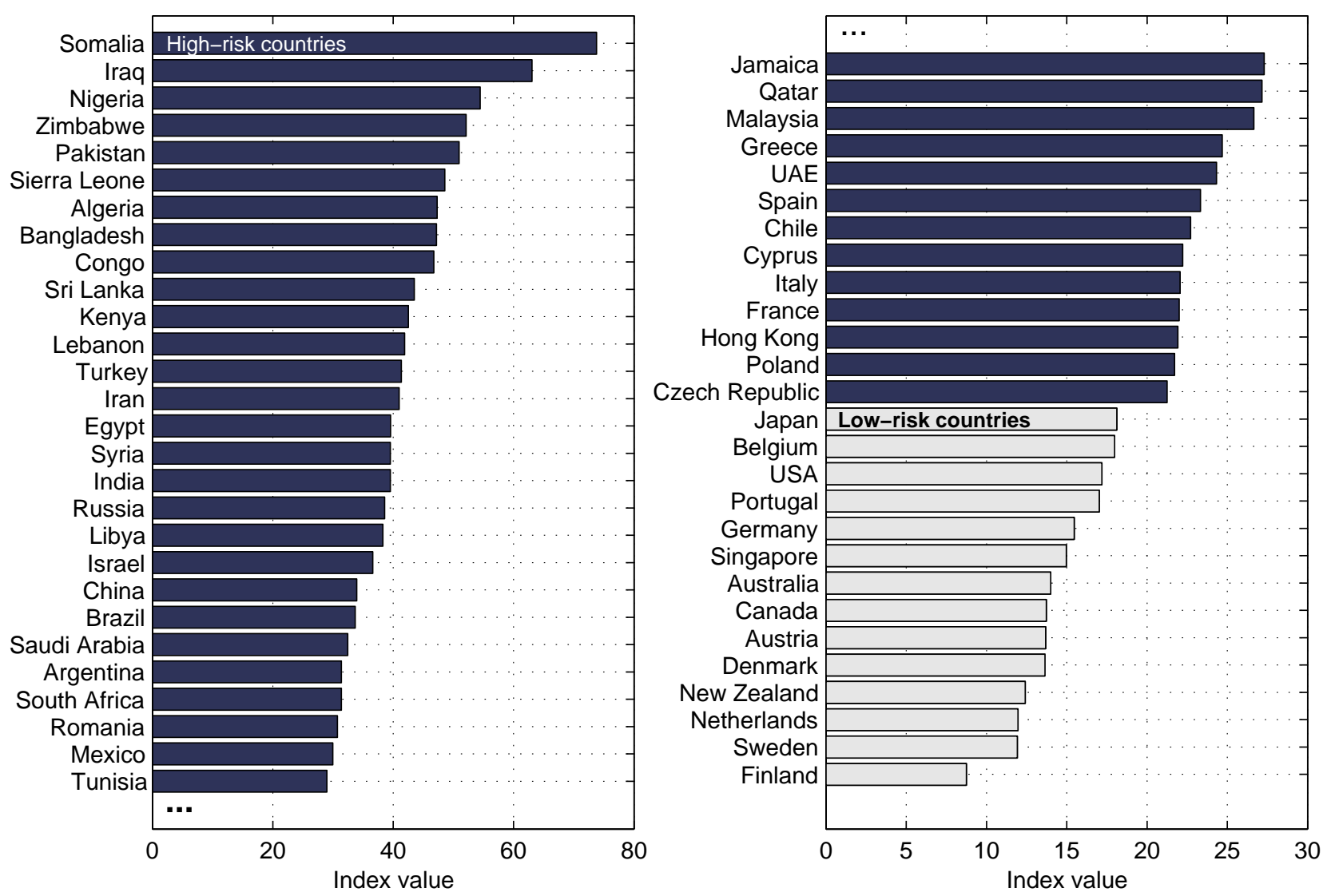
Figure A.3

Cross-ward distribution of demographic, social and economic variables

The figure shows the distribution of selected variables, across the set of 624 London wards. We report the unit of measurement in parentheses, below the variable name.
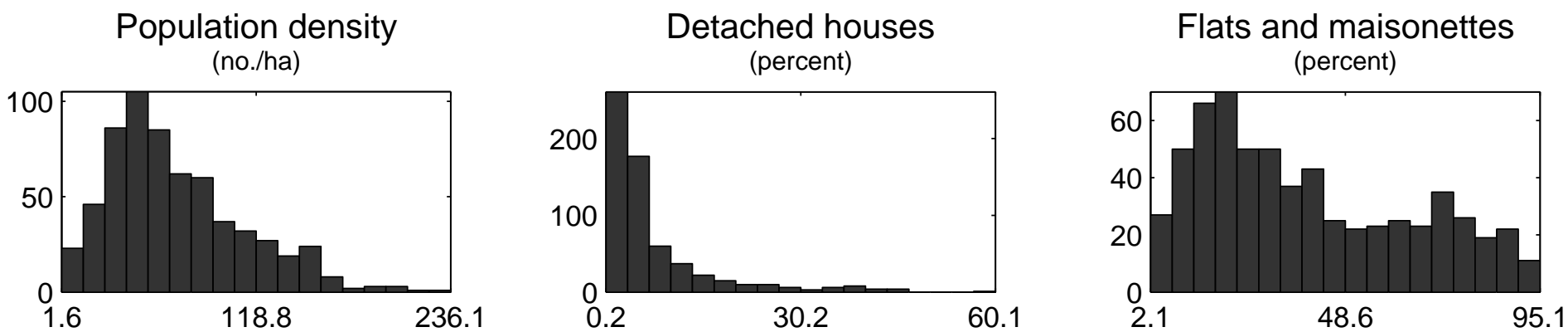

Cars per household
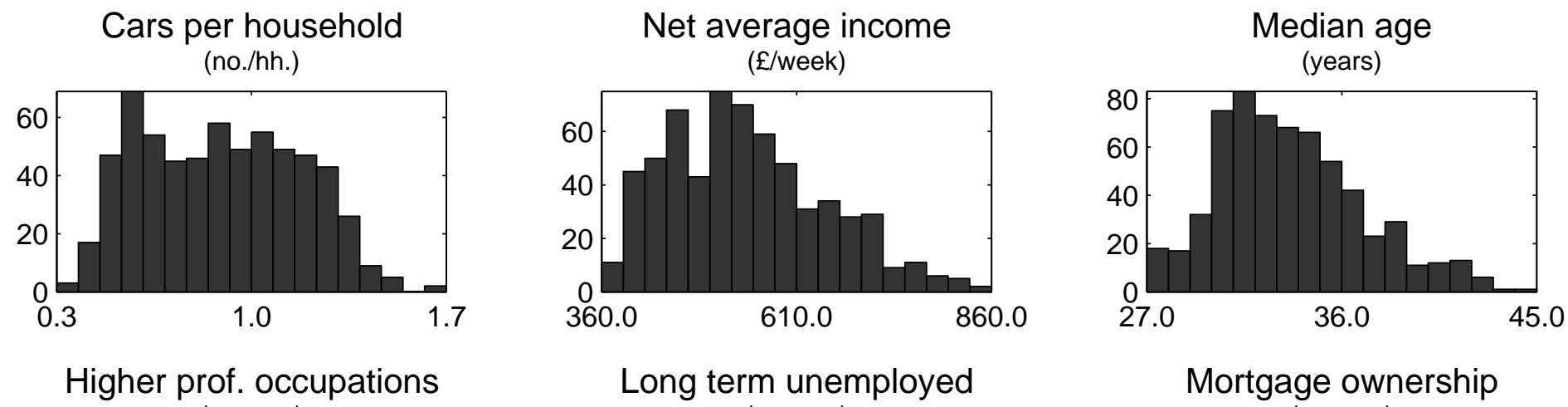

Higher prof. occupations
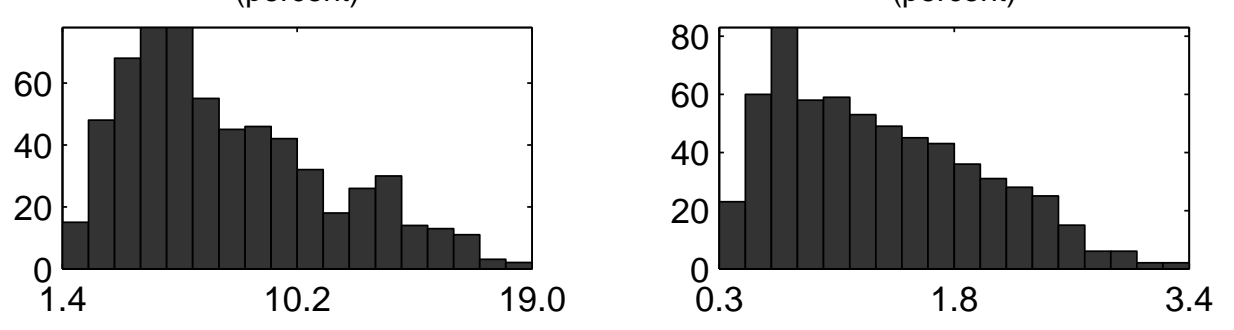

Mortgage ownership (percent)

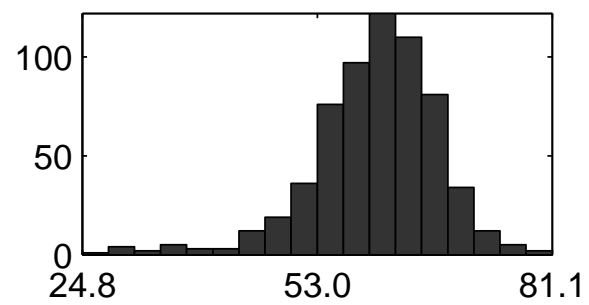


FiguRE A.4

Cross-ward distribution of the foreign-born people shares

The figure shows the distribution of the shares of people born in respective countries or country groups, across the set of 624 London wards. We report the shares in percent of the total ward population.
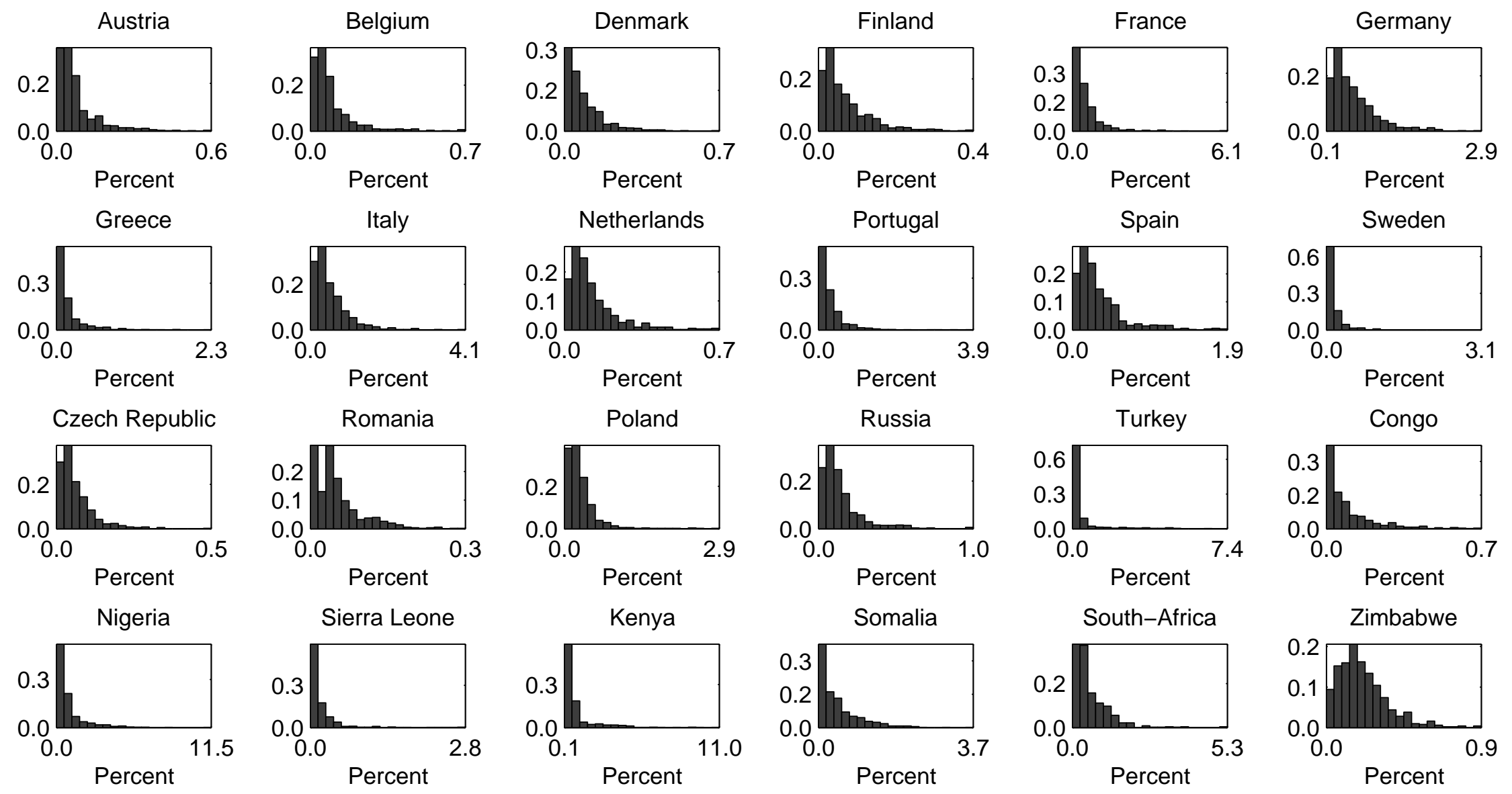
FiguRE A.4

Cross-ward distribution of the foreign-born people shares

(continued)
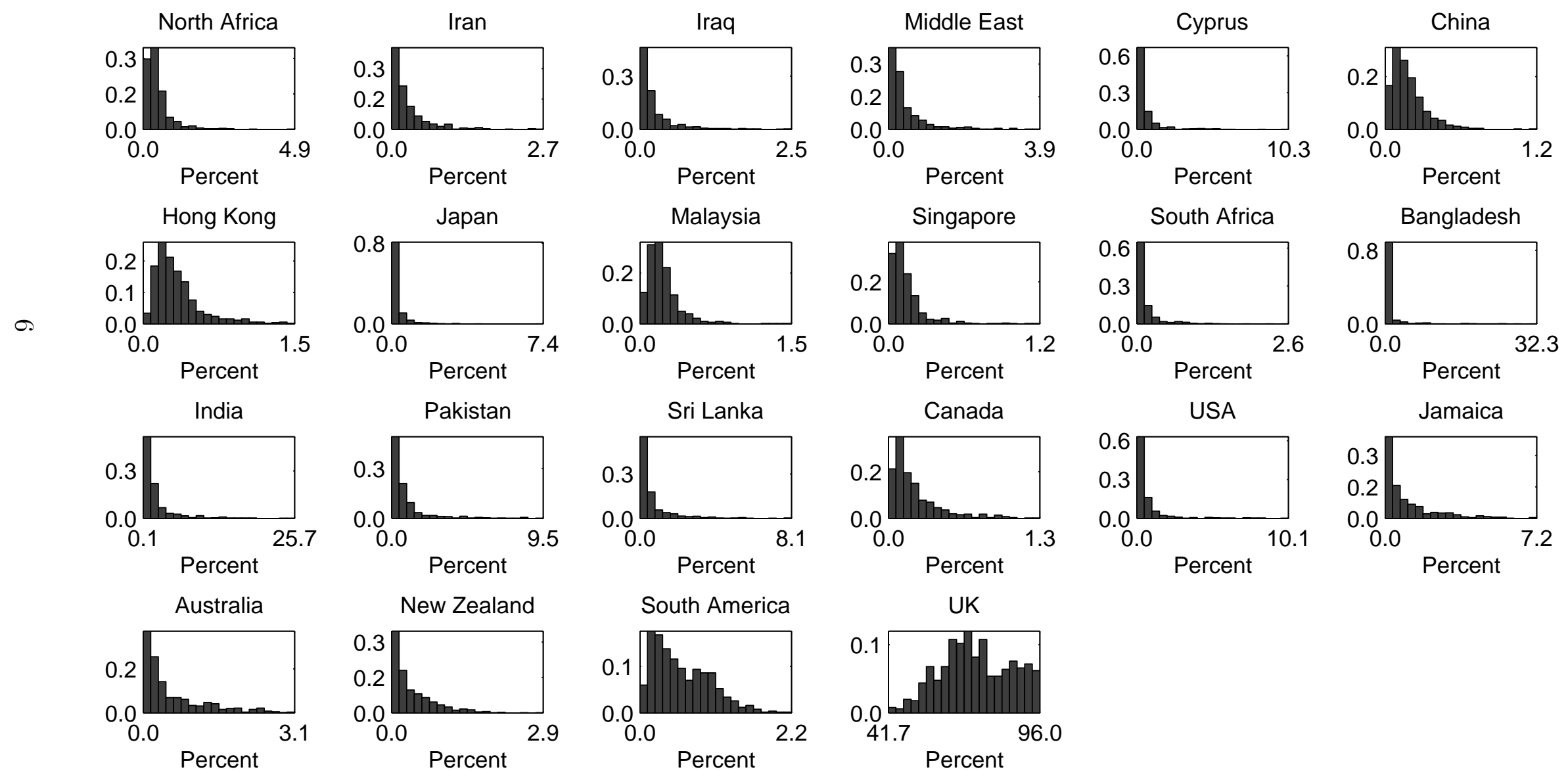


\section{FiguRE A.5}

Time series of capital flows into London's commercial real estate market

The figure reports the evolution of capital inflows into the London commercial real estate market and their relationship with political risk. The data source is Real Capital Analytics. We report the sum of the total inflows from our sample countries with relatively high levels of political risk, as listed in Figure A.2.

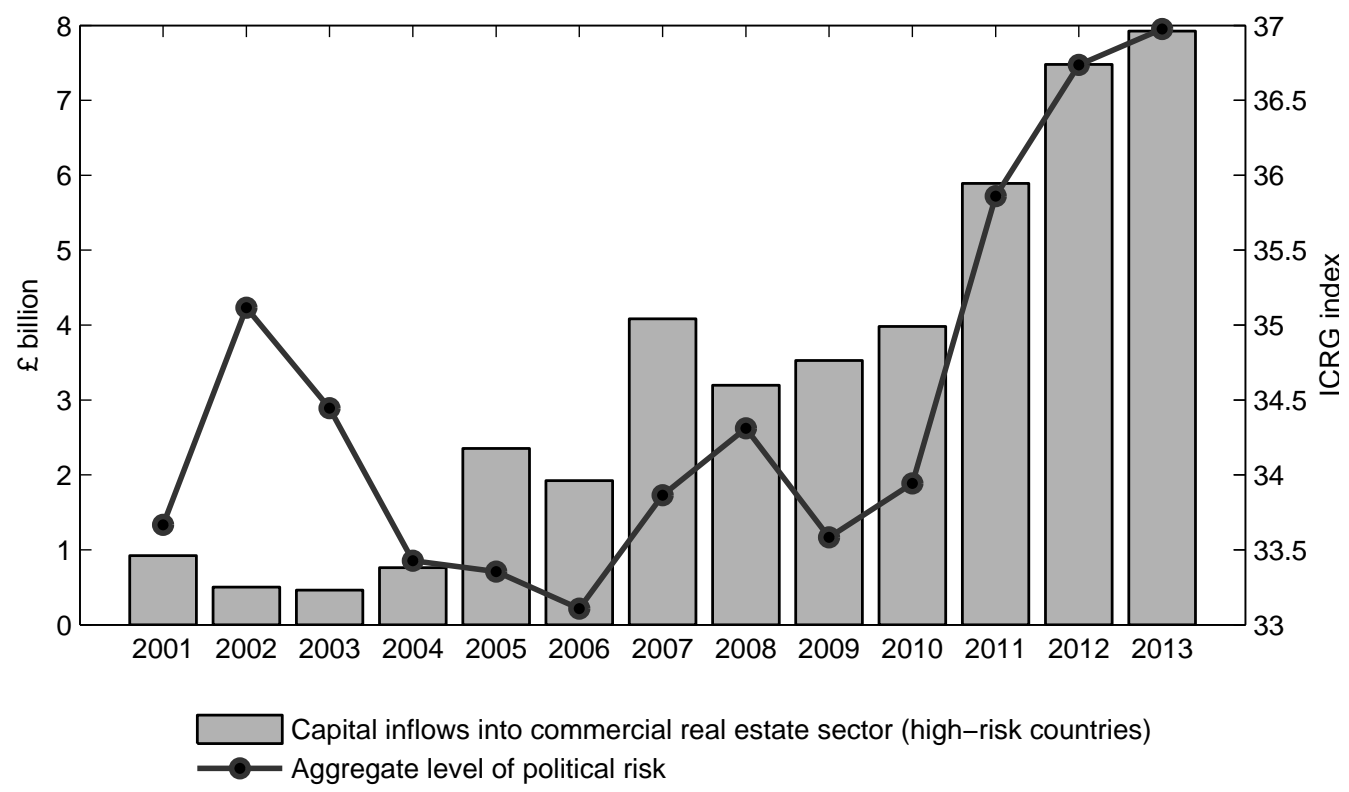


Figure A.6

Foreign political risk and migration into the UK

In this figure, we report the number of additional visas granted by the UK in 2013, relative to 2008 . The line indicates univariate cross-country fitted values. On the horizontal axis, we report the change in political risk (measured by the ICRG index) between 2008 and 2013. In this representation, we exclude countries for which the number of visas or the number of people which enter the UK are equal to zero.

\section{Total number of visas}

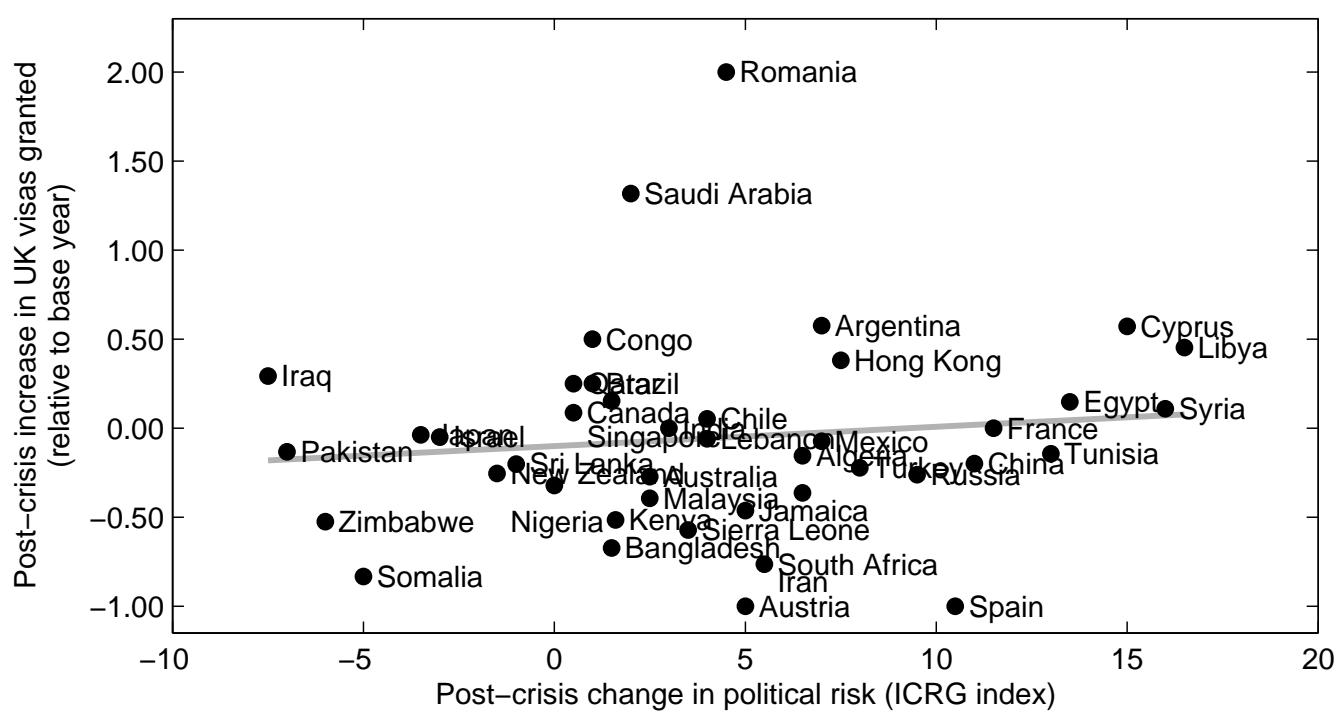




\section{FiguRE A.7}

\section{Robustness check: clustering at the level of world regions}

The figure reports the estimated average response of house prices in wards with high shares of foreign born people, following a shift to the high-risk regime. The empirical specifications corresponds to the following equations:

$$
\Delta s_{t}^{k}=\mu^{k}+\delta_{t}+\rho \Delta s_{t-1}^{k}+\sum_{l=1}^{L} \zeta_{l} z_{t-l}^{k}+u_{t}^{k}, \text { and } \Delta \nu_{t}^{k}=\omega^{k}+\tau_{t}+\gamma \Delta \nu_{t-1}^{k}+\sum_{l=1}^{L} \eta_{l} z_{t-l}^{k}+\epsilon_{t}^{k}
$$

where $z_{t}^{k}$ is the risk indicator of the ICRG index of political risk. In our benchmark specification, we consider the case $L=20$ quarters. In Panel B, we report analogous impulse responses for the cross-ward spreads in transaction volumes and mortgage originations. The gray shaded areas (Registry dataset) and the dotted lines (Loans dataset) indicate 90\% confidence intervals, based on double clustered standard errors at the region and year level. We determine the statistical significance of accumulated impulse responses and impute corresponding confidence intervals based on the critical values of the F-test.

\section{Panel A}

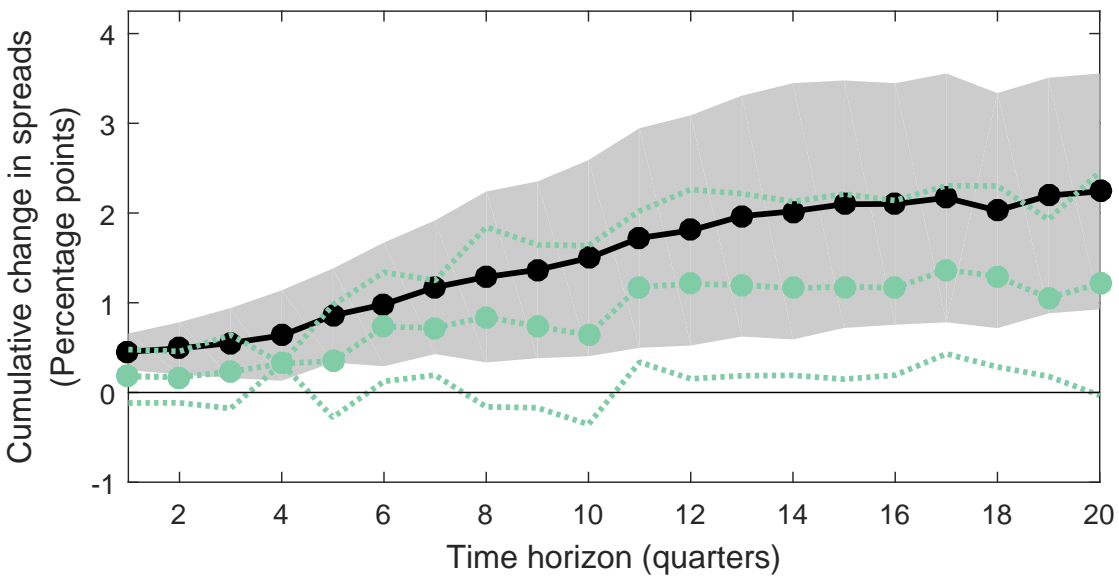

$\longrightarrow$ Registry dataset $\cdots \cdots$ Loans dataset

Panel B

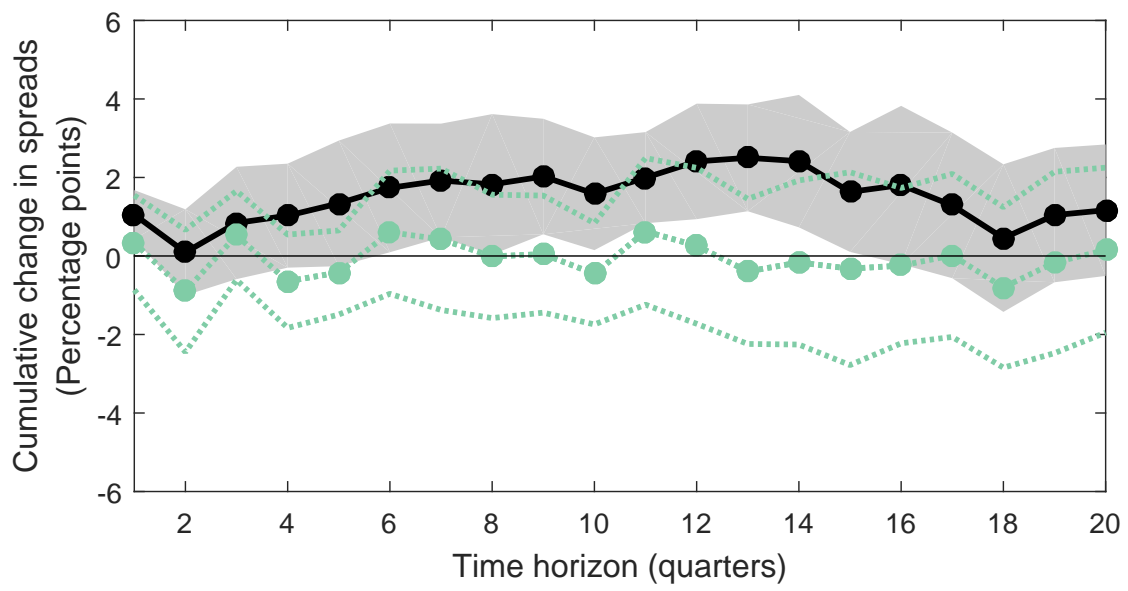

- Volume of transactions ........ Volume of mortgage loans 


\section{TABLE A.1}

Summary statistics across wards

The table reports mean values for selected variables, calculated for the wards in the top quintile of the respective distributions, according to the share of people born in our set of country regions. The population density is calculated using the usual resident population and the size of the area in hectares. The market share of flats indicates all people who were usually resident in the area at the time of the 2001 census, who lived in an unshared dwelling, that was a flat, maisonette or apartment, as a percent of the total ward population. Net average income levels are estimated by the UK Office for National Statistics and expressed in pounds sterling per week. The information on vehicle ownership is based on the number of cars or vans owned, or available for use, by one or more members of a household, including company cars or vans available for private use. The share of people in higher professional occupations is reported as classified by the UK Office for National Statistics. The ward-level degree of mortgage ownership is given by the number of households in the area at the time of the 2001 census, who are holders of a residential mortgage, as a fraction of the total number of homeowners.

\begin{tabular}{llcccccc}
\hline & & $\begin{array}{c}\text { Population } \\
\text { density } \\
(\text { no/ha })\end{array}$ & $\begin{array}{c}\text { Market share } \\
\text { of flats } \\
\text { (percent) }\end{array}$ & $\begin{array}{c}\text { Net } \\
\text { income } \\
(£ / \text { week })\end{array}$ & $\begin{array}{c}\text { Cars per } \\
\text { household } \\
\text { (no/hh. })\end{array}$ & $\begin{array}{c}\text { Higher prof. } \\
\text { occupations } \\
\text { (percent) }\end{array}$ & $\begin{array}{c}\text { Mortgage } \\
\text { holders } \\
\text { (percent) }\end{array}$ \\
\hline \hline Top 20\% of wards with highest \\
shares of people born in: & Southern Europe & 110.99 & 68.51 & 580.80 & 0.63 & 10.86 & 55.71 \\
& Eastern Europe & 85.56 & 50.59 & 603.28 & 0.81 & 10.60 & 55.41 \\
& Russia & 94.08 & 59.84 & 590.08 & 0.73 & 10.85 & 54.81 \\
& Middle East & 90.17 & 54.38 & 537.10 & 0.73 & 8.51 & 57.16 \\
& Africa & 77.09 & 40.36 & 490.24 & 0.82 & 6.27 & 61.35 \\
& South Asia & 76.17 & 34.04 & 497.10 & 0.86 & 6.22 & 61.24 \\
& Asia-Pacific & 97.42 & 62.38 & 641.28 & 0.73 & 12.74 & 54.92 \\
& South and Central America & 89.76 & 48.87 & 484.24 & 0.68 & 6.52 & 63.81 \\
& UK & 38.04 & 14.95 & 553.20 & 1.15 & 4.92 & 58.86 \\
\hline Full sample of wards & & 70.68 & 39.41 & 546.14 & 0.88 & 7.62 & 59.88 \\
\hline
\end{tabular}


Figure A.8

Nationalities of buyers in the Prime Central London area

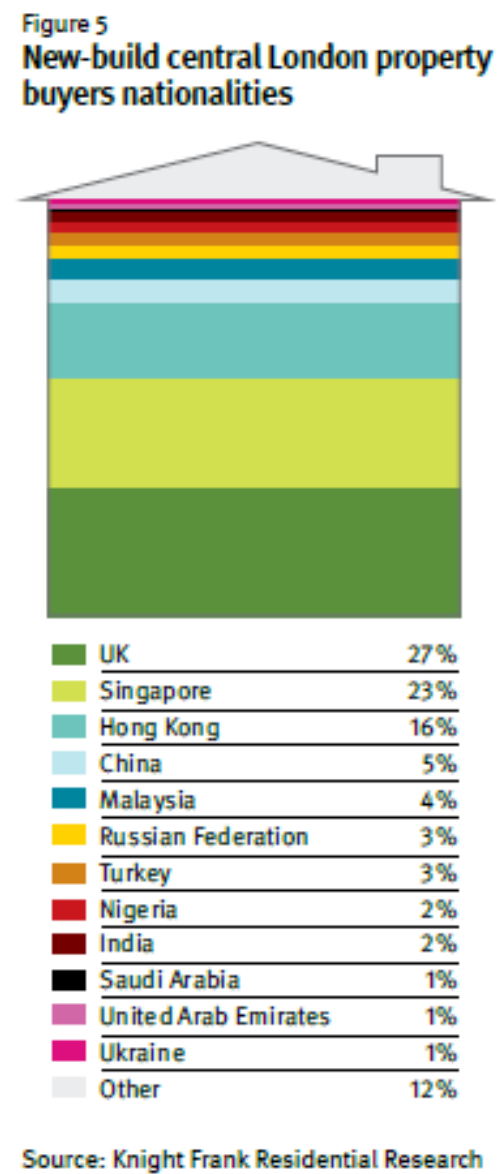




\section{TABLE A.2}

\section{Robustness of the results}

The table reports estimated cumulative impulse responses of cross-ward price spreads to a foreign risk shock, based on the following model specification:

$$
\Delta s_{t}^{k}=\mu^{k}+\delta_{t}+\rho \Delta s_{t-1}^{k}+\sum_{l=1}^{L} \zeta_{l} z_{t-l}^{k}+u_{t}^{k}
$$

where $z_{t}^{k}$ is an indicator variable which takes the value of one if the respective risk measure is in the high-risk regime. We report impulse responses at a horizon of 2 years (8 quarters). The estimated impulse responses are multiplied by 100, for easier interpretation as percentage points. We use clustered standard errors at the country and year level. *,**, *** denote statistical significance at the $10 \%, 5 \%$, and $1 \%$ level respectively.

Robustness check:

Property characteristics x ward fixed effects

Foreign demand effect $1.27^{* *}$

Robustness check:

Benchmark estimation excluding France

Foreign demand effect $1.29^{* *}$

Placebo test:

Benchmark estimation for low-risk countries

Foreign demand effect $\quad-0.35$


TABLE A.3

The role of individual components of the ICRG risk index

Panel A reports the contribution of each of the 12 individual components to the total variation of quarterly changes of the ICRG index. Panel B reports estimation results from the following estimation specification:

$$
\Delta s_{t}^{k}=\mu^{k}+\delta_{t}+\rho \Delta s_{t-1}^{k}+\sum_{j=1}^{J=12} \zeta_{j} Z_{t-1}^{k}+u_{t}^{k},
$$

where $Z_{t}^{k}$ is the level of the ICRG index of political risk in quarter $t$ in country $k$. We use double clustered standard errors at the country and year level. ${ }^{*},{ }^{* *},{ }^{* * *}$ denote statistical significance at the $10 \%, 5 \%$, and $1 \%$ level, respectively.

\section{Panel A}

Variance decomposition of quarterly ICRG growth rates

\begin{tabular}{lr}
\hline \hline Government instability & $19.8 \%$ \\
Internal conflict & $17.3 \%$ \\
Investment profile & $17.0 \%$ \\
External conflict & $12.1 \%$ \\
Socioeconomic conditions & $7.2 \%$ \\
Democratic accountability & $6.9 \%$ \\
Law and order & $4.6 \%$ \\
Military in politics & $4.5 \%$ \\
Corruption & $4.0 \%$ \\
Ethnic tensions & $3.7 \%$ \\
Religion in politics & $2.1 \%$ \\
Bureaucratic quality & $0.8 \%$ \\
\hline
\end{tabular}

\section{Panel B}

Contribution of individual ICRG components to foreign demand effects

\begin{tabular}{ll}
\hline \hline Religion in politics & $0.184^{*}$ \\
External conflict & $0.120^{* *}$ \\
Internal conflict & $0.080^{*}$ \\
Investment profile & $0.075^{* *}$ \\
Bureaucratic quality & 0.059 \\
Socioeconomic conditions & 0.021 \\
Ethnic tensions & 0.007 \\
Military in politics & -0.019 \\
Government instability & -0.031 \\
Corruption & -0.090 \\
Democratic accountability & -0.114 \\
Law and order & $-0.256^{*}$ \\
\hline
\end{tabular}


TABLE A.4

Cross-ward correlation between country of birth and ethnic group

The table reports correlation coefficients between the ward-level share of people born in a given country and the share of the respective ethic group, relative to the total population of the ward. The difference between the two is that the latter measure also includes UK citizens and those that were born in the UK, but which belong to an ethnic group defined by the country of origin of their ancestors. We are only able to compute these statistics for a small subset of the countries/world regions because the ethnic composition is recorded in the 2001 census just for the nationalities/ethnic groups listed below.

\begin{tabular}{ll}
\hline \hline Bangladesh & 0.9991 \\
Pakistan & 0.9948 \\
India & 0.9751 \\
China & 0.8148 \\
Africa & 0.7579 \\
\hline
\end{tabular}


TABle A.5

The role of isolated risk events

The table reports estimated cumulative impulse responses of cross-ward price spreads to a foreign risk shock, based on the following model specification:

$$
\Delta s_{t}^{k}=\mu^{k}+\delta_{t}+\rho \Delta s_{t-1}^{k}+\sum_{l=1}^{L} \zeta_{l} z_{t-l}^{k}+\sum_{l=1}^{L} \xi_{l} \bar{z}_{t-l}^{k}+u_{t}^{k}
$$

Here, $\bar{z}_{t}^{k}$ is an indicator variable which takes the value of one if two conditions are met: i) the ICRG index is in the high-risk regime in quarter $t$ and ii) the ICRG index is not in the high-risk regime in any of $h$ quarters before and after $t$. We report impulse responses at a horizon of 2 years ( 8 quarters). The estimated impulse responses are multiplied by 100, for easier interpretation as percentage points. We use clustered standard errors at the country and year level. *, **, *** denote statistical significance at the $10 \%, 5 \%$, and $1 \%$ level respectively.

\begin{tabular}{lccccc}
\hline & \multicolumn{5}{c}{$\bar{z}_{t}^{k}=1$ if no other risk event within: } \\
& 3 quarters & 4 quarters & 5 quarters & 6 quarters & 7 quarters \\
\hline \hline Foreign demand effect & $1.30^{* *}$ & $1.35^{* *}$ & $1.35^{* *}$ & $1.37^{* *}$ & $1.35^{* *}$ \\
- Isolated events & 1.12 & 1.11 & 0.76 & 0.70 & 0.65 \\
\hline Number of obs. & 1705 & 1705 & 1705 & 1705 & 1705 \\
Adj. $\mathrm{R}^{2}$ & 0.38 & 0.38 & 0.38 & 0.38 & 0.38 \\
\hline
\end{tabular}




\section{Immigration and House Prices}

One of the possibilities we consider in our specifications is that cross-border property investments into London are driven purely by a desire to move capital away from regions with high political and economic uncertainty, without any associated immigration of foreign purchasers into London. Yet another possibility is that safe-haven property investments incorporate an implicit or explicit future consideration by purchasers of future London-bound immigration. If this is indeed the case, when political or economic risks actually materialize, relatively fast moving capital flows towards London properties may be followed by relatively slow-moving subsequent increases in immigration. We therefore investigate whether price increases in wards with higher shares of foreign-born people are a signal of increased future immigration into those wards.

Any such immigration might be expected to occur at a much lower frequency than the safe-haven price effects, with longer-lasting effects on the demographic structure of London. Given data availability, we use the U.K. Office for National Statistics census information recorded in 2001 and 2011 to test this hypothesis.

We estimate the following regressions:

$$
\begin{aligned}
\Delta f_{w, 2011}^{k} & =\alpha+\rho^{k} f_{w, 2001}^{k}+\pi_{1}^{k} \Delta \ln P_{w, 2001}+e_{w, 2011}^{k}, \\
\Delta f_{w, 2011}^{k}= & \alpha+\rho^{k} f_{w, 2001}^{k}+\pi_{2}^{k} \Delta \ln \bar{P}_{w, 2001}+\pi_{3}^{k} \Delta u_{w, 2001}+e_{w, 2011}^{k}
\end{aligned}
$$

In these regressions, $\Delta \ln P_{w, 2001}$ is the actual $\log$ price change between 1996 and 2001 in ward $w$, computed by equal-weighting prices of all properties transacted in ward $w$ in each of those years. $\Delta \ln \bar{P}_{w, 2001}$ and $\Delta u_{w, 2001}$ are constructed by controlling for variation in price-impacting hedonic characteristics of properties at the ward level. $\Delta \ln \bar{P}_{w, 2001}$ is the change in the fitted value of the price arising from hedonic price regressions in 1996 and 2001 and $\Delta u_{w, 2001}$ is the difference in the residuals from these regressions between these two time periods.

In our interpretation of the results, we identify the coefficient $\pi_{3}^{k}$ with safe-haven demand effects for the purposes of this auxiliary exercise. We are limited by the fact that we only have two available vintages of the census data, from 2001 and 2011. Consequently, we are only able to run a cross-sectional regression to explain variation in the immigration share between these two vintages. This means that we cannot use time-variation in economic and political risk in our attribution of the impacts of safehaven demand effects on price, and hence, we simply attribute unexplained-by-hedonics variation in prices between 1996 and $2001\left(\Delta u_{w, 2001}\right)$ to safe-haven demand effects. If 
other factors are responsible for this unexplained variation in prices, as long as they are uncorrelated with future immigration, we would expect them to act as classical measurement error, biasing $\pi_{3}^{k}$ towards zero.

Together, specifications (A.1) and (A.2) allow us to check whether price changes have a role in predicting subsequent changes in future immigration over and above the lagged level of immigrants from country $k$ residing in ward $w$. These regressions, while interesting, are only able to provide suggestive evidence on the interplay between house prices and immigration patterns, both across wards and through time. Figure A.9 shows estimates of equations (A.1) and (A.2). The figure shows that price changes in wards occurring between 1996 and 2001 are a statistically significant and positive predictor of immigration occurring thereafter from Spain, Italy, Portugal, and China. The first bar in these plots corresponds to actual pre-2001 price changes, while the second bar corresponds to the component of the price changes which is unexplained by property and ward characteristics. It is clear from these plots that the variation in hedonic characteristics between 1996 and 2001 is not responsible for the predictive power of prices for the immigration shares. These results are consistent with safe-haven demand causing price pressure in ward-level house prices which subsequently results in immigration flows from these countries. However, it is worth noting here that we view this part of the analysis as far less precise than our earlier specifications which explain house price movements.

The figures also show that these unexplained price changes are negative forecasters of immigration from the South Asian countries. This highlights another important limitation of this analysis of immigration, namely, that unexplained changes in wardlevel prices may be generated by a number of potential determinants, including safe haven flows from other countries. This in turn might act as a deterrent to relatively less well-off immigrants from other regions of the world. So, for example, if certain wards experienced unusual price increases from 1996 to 2001 on account of safe-haven demand from, say, Russia, and if immigrants from, say, Sri Lanka shied away from wards with high price increases not caused by their own house purchases, then this would explain the negative coefficients $\pi_{3}^{k}$ that we detect for Sri Lanka. 
Figure A.9

Relationship between house prices and immigration shares

The figure reports the coefficients $\pi_{1}^{k}$ and $\pi_{3}^{k}$ from the regressions:

$$
\begin{aligned}
& \Delta f_{w, 2011}^{k}=\alpha+\rho^{k} f_{w, 2001}^{k}+\pi_{1}^{k} \Delta \ln P_{w, 2001}+e_{w, 2011}^{k}, \text { and } \\
& \Delta f_{w, 2011}^{k}=\alpha+\rho^{k} f_{w, 2001}^{k}+\pi_{2}^{k} \Delta \ln \bar{P}_{w, 2001}+\pi_{3}^{k} \Delta u_{w, 2001}+e_{w, 2011}^{k}
\end{aligned}
$$

Here, $\Delta \ln P_{w, 2001}$ is the actual $\log$ price change between 1996 and 2001 in ward $w$, computed by equal-weighting prices of all properties transacted in ward $w$ in each of those years. $\Delta u_{w, 2001}$ is the residual price change in ward $w$, constructed by controlling for variation in price-impacting hedonic characteristics of properties at the ward level. $\Delta \ln \bar{P}_{w, 2001}$ is the component of total price changes which can be attributed to changes in characteristics between the two time periods. The price variables are normalized by subtracting the in-sample mean and dividing by the standard deviation. The estimation sample consists of the 624 London wards. The total length of the bars indicates point estimates and the shaded areas correspond to $95 \%$ confidence intervals. The estimated standard errors are White heteroskedasticity-robust.
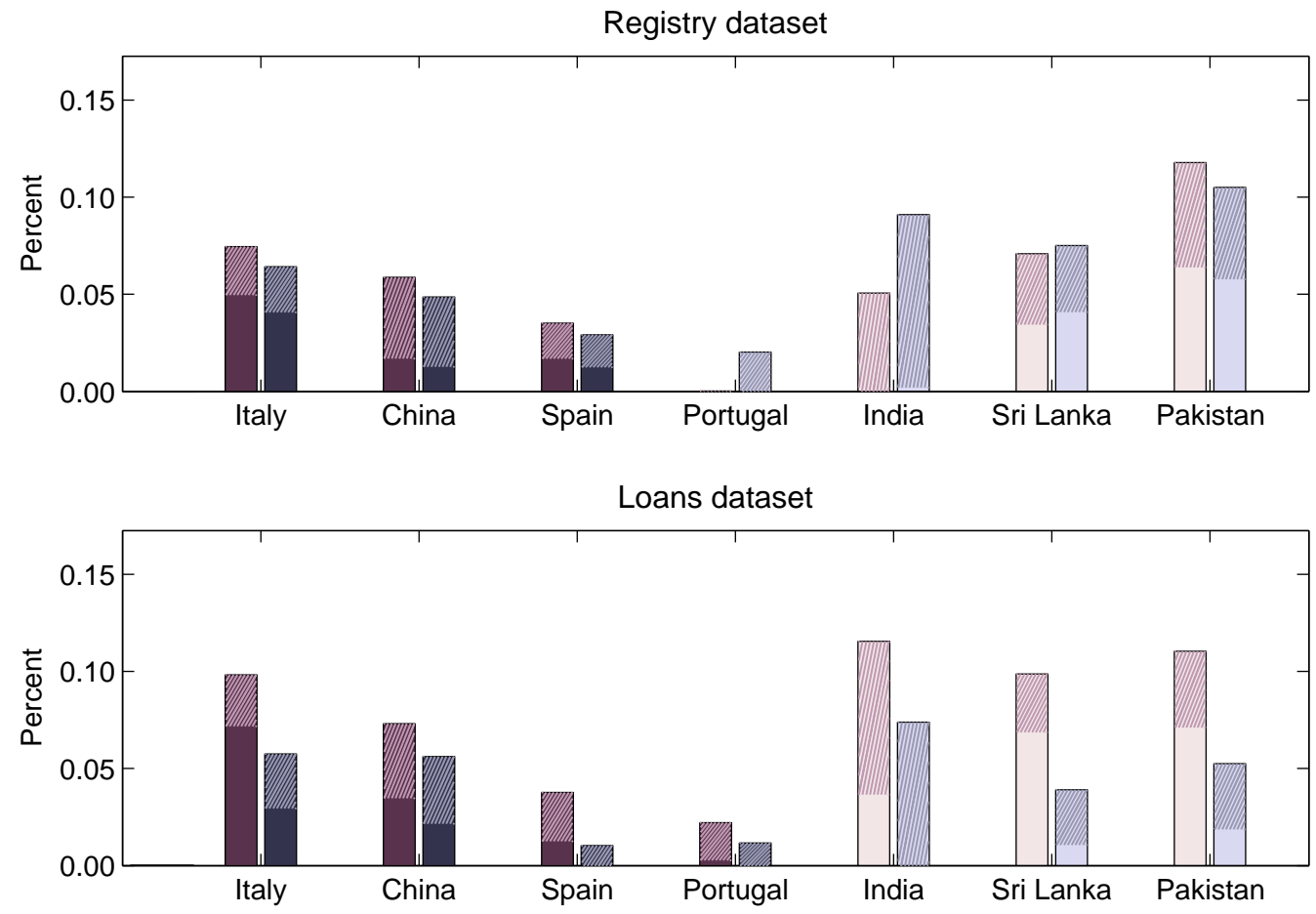

Total average price changes

Residual price changes 